Prepared for the U.S. Department of Energy under Contract DE-AC05-76RL01830

\title{
Validation of New Process Models for Large Injection-Molded Long- Fiber Thermoplastic Composite Structures
}

\author{
Ba Nghiep Nguyen ${ }^{(a)}$, Xiaoshi Jin ${ }^{(b)}$, Jin Wang ${ }^{(b)}$, \\ Vlastimil Kunc ${ }^{(\mathrm{c})}$, Charles L. Tucker III ${ }^{(\mathrm{d})}$
}

(a) Pacific Northwest National Laboratory, P.O. Box 999, Richland, WA 99352

(b) Autodesk, Inc. at Ithaca, NY 14850

(c) Oak Ridge National Laboratory, P.O. Box 2009, Oak Ridge, TN 37831

(d) University of Illinois at Urbana-Champaign, Department of Mechanical Science and Engineering, Urbana, IL 61801

\section{February 2011}




\section{DISCIAAIMER}

This report was prepared as an account of work sponsored by an agency of the United States Government. Neither the United States Government nor any agency thereof, nor Battelle Memorial Institute, nor any of their employees, makes any warranty, express or implied, or assumes any legal liability or responsibility for the accuracy, completeness, or usefulness of any information, apparatus, product, or process diselosed, or represents that its use would not infringe privately owned rights. Reference herein to any specific commercial product, process, or service by trade name, trademark, manufacturer, or otherwise does not necessarily constitute or imply its endorsement, recommendation, or favoring by the United States Government or any agency thereof, or Battelle Memorial Institute. The views and opinions of authors expressed herein do not necessarily state or rellect those of the United States Government or any agency thereof.

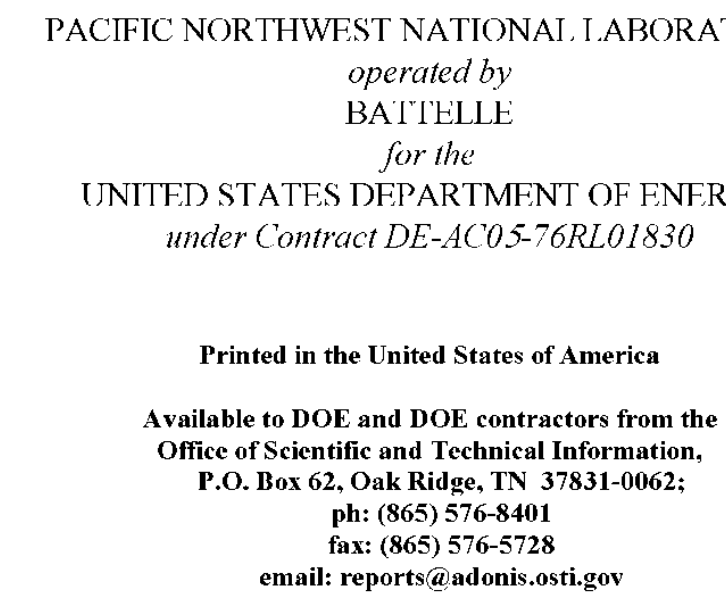

Available to the public from the National Technical Information Service, U.S. Department of Commerce, 5285 Port Royal Rd., Springfield, VA 22161 ph: (800) 553-6847 fax: (703) 605-6900 email: orders@ntis.fedworld.gov online ordering: http://www.ntis.gov/ordering.htm

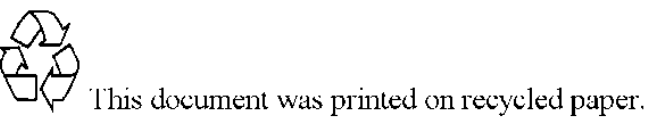

(9/2003) 


\title{
Validation of New Process Models for Large Injection-Molded Long-Fiber Thermoplastic Composite Structures
}

\author{
Ba Nghiep Nguyen ${ }^{(a)}$, Xiaoshi Jin ${ }^{(b)}$, Jin Wang ${ }^{(b)}$, \\ Vlastimil Kunc ${ }^{(\mathrm{c})}$, Charles L. Tucker III ${ }^{(\mathrm{d})}$
}

\begin{abstract}
(a) Pacific Northwest National Laboratory, P.O. Box 999, Richland, WA 99352
(b) Autodesk, Inc. at Ithaca, NY 14850

(c) Oak Ridge National Laboratory, P.O. Box 2009, Oak Ridge, TN 37831

(d) University of Illinois at Urbana-Champaign, Department of Mechanical Science and Engineering, Urbana, IL 61801
\end{abstract}

\section{February 2012}

Prepared for

the U.S. Department of Energy

under Contract DE-AC05-76RL01830 



\section{Executive Summary}

Recently, long-fiber thermoplastic (LFT) composites have attracted great interest within the automotive industry since these materials offer much better structural performance (e.g. higher elastic moduli, strength, and durability) than their short-fiber analogues, and they can be processed through injection molding with some specific tool design. However, to be able to compute the properties of injection molded LFTs, there is an important need to develop process models and computational tools to predict the microstructure of these composites. The microstructure of injection molded LFTs is governed by i) flow-induced fiber orientation, ii) fiber breakage during injection molding, and iii) processing conditions (e.g. pressure, mold and melt temperatures, mold geometries, injection speed, etc.). Under the Cooperative Research and Development Agreement (CRADA) Nr. PNNL/260 between Battelle as Operator of Pacific Northwest National Laboratory (PNNL) and Autodesk, Inc. (hereinafter "Autodesk"), process models developed by the University of Illinois for predicting fiber length and orientation distributions in injection-molded LFTs were implemented in the research versions of Autodesk Moldflow Insight (AMI) software packages (hereinafter "Moldflow"). These models were then used in the Moldflow injection molding simulations of simple and small-scale long-glassfiber/polypropylene samples.

The scope of work for the CRADA Nr. PNNL/304 between Battelle PNNL and Autodesk aims at rendering the developed technologies for LFTs more robust through further validating them for large representative long-glass-fiber thermoplastic structures that were injection-molded using the mold offered by the Automotive Composite Consortium (ACC). This validation work is critical before the Autodesk Moldflow Insight research versions containing these new process models can be applied to more complex LFT parts used by the automotive and plastics industries. This CRADA supports the DOE/PNNL/ORNL Predictive Engineering project titled: "Engineering Property Prediction Tools for Tailored Polymer Composite Structures." 



\section{Contents}

Executive Summary .................................................................................... iii

Contents......................................................................

List of Figures................................................................2

List of Tables..............................................................4

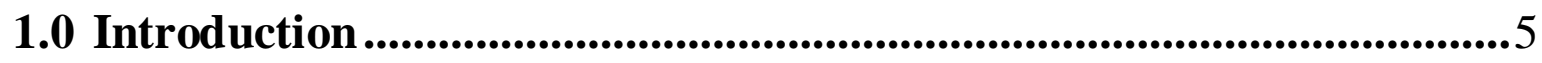

2.0 Process Models Developed for LFTs ...................................................5

2.1 The Phelps-Tucker Anisotropic Rotary Diffusion - Reduced Strain Closure Model ......... 5

2.2 The Phelps-Tucker Fiber Length Attrition Model ........................................................ 7

3.0 Summary of New Process Models Implementations............................8

3.1 Dialog Box Designs for the ARD-RSC Model..............................................8

3.2 Dialog Box Designs for the Fiber Length Attrition Model....................................8

4.0 Processing Conditions and Parameters ................................................10

5.0 AMI Analyses of ACC Plaques ............................................................11

5.1 Identification of the ARD-RSC Model Parameters............................................14

5.2 Identification of the Fiber Length Attrition Model Parameters.................................16

5.3 Fiber Orientation and Length Results for the Dow Chemical Glass/PP Plaques............17

5.4 Fiber Orientation and Length Results for the DuPont Glass/PA6,6 Plaques..................30

6.0 Conclusions ...............................................................................................42

7.0 Acknowledgements ........................................................................42

8.0 References ....................................................................................................44 


\section{List of Figures}

Figure 1. Dialog boxes for introducing parameters of the ARD-RSC model $\ldots \ldots \ldots \ldots \ldots \ldots \ldots \ldots \ldots \ldots . . . \ldots$ Figure 2. Dialog box for selecting fiber breakage calculation for a long fiber material.....................9

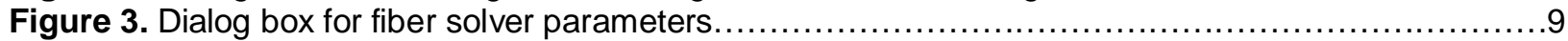

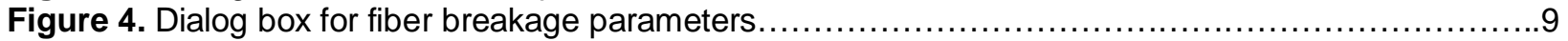

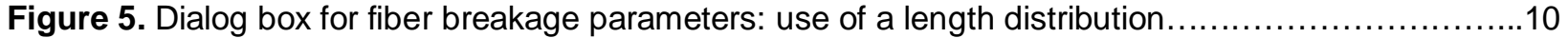

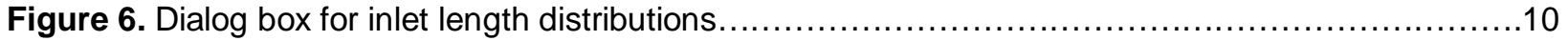
Figure 7. The AMI mid-plane model for the injection molding analyses of the ACC edge-gated plaques the feeding system and gate are modeled with beam elements........................................ Figure 8. The AMI mid-plane model for the injection molding analyses of the ACC center-gated

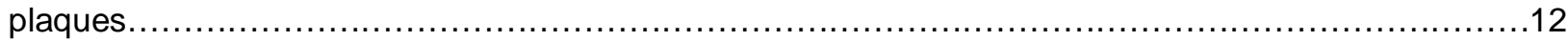

Figure 9. The AMI 3-D model for the injection molding analyses of the ACC edge-gated plaques........13

Figure 10. The AMI 3-D model for the injection molding analyses of the ACC center-gated plaques......13 Figure 11. Regions A, B and C being $25.4 \mathrm{~mm}$ long along a centerline at $38 \mathrm{~mm}, 140 \mathrm{~mm}$, and $241 \mathrm{~mm}$ from the injection locations of the ACC center-gated plaques were taken for fiber length and orientation

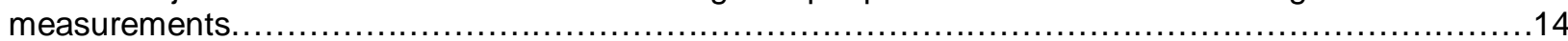
Figure 12. Regions A, B and C being $25.4 \mathrm{~mm}$ long along the centerline at $38 \mathrm{~mm}, 140 \mathrm{~mm}$, and $241 \mathrm{~mm}$ from the gate of the ACC edge-gated plaques were taken for fiber length and orientation

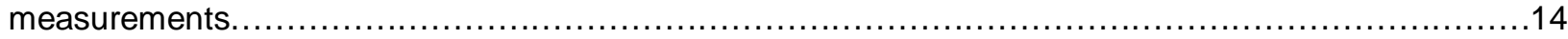

Figure 13. Predicted and measured second-order orientation tensor components (a) $A_{11}$ and (b) $A_{22}$ for

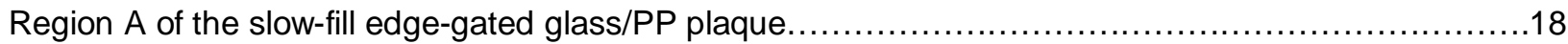
Figure 14. Predicted and measured second-order orientation tensor components (a) $A_{11}$ and (b) $A_{22}$ for

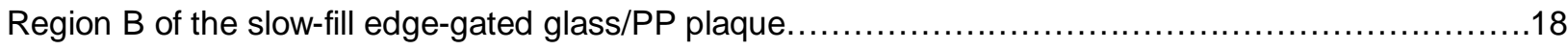
Figure 15. Predicted and measured second-order orientation tensor components (a) $A_{11}$ and (b) $A_{22}$ for Region $\mathrm{C}$ of the slow-fill edge-gated glass/PP plaque................................................. Figure 16. Predicted and experimental weight-average lengths for the slow-fill edge-gated glass/PP

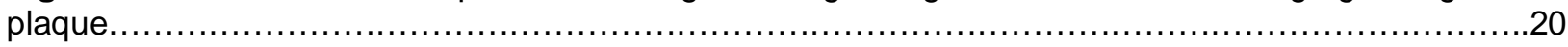
Figure 17. Predicted and measured second-order orientation tensor components (a) $A_{11}$ and (b) $A_{22}$ for

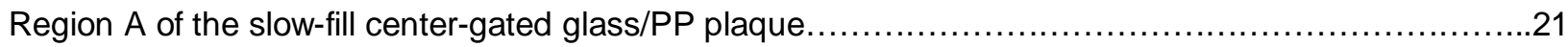
Figure 18. Predicted and measured second-order orientation tensor components (a) $A_{11}$ and (b) $A_{22}$ for

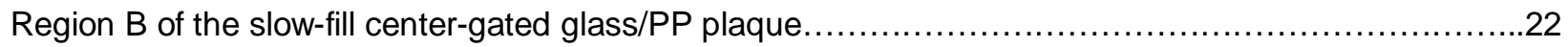
Figure 19. Predicted and measured second-order orientation tensor components (a) $A_{11}$ and (b) $A_{22}$ for

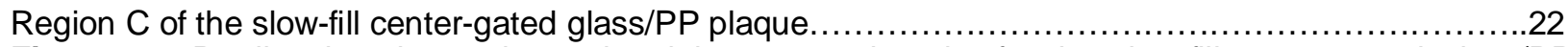
Figure 20. Predicted and experimental weight-average lengths for the slow-fill center-gated glass/PP

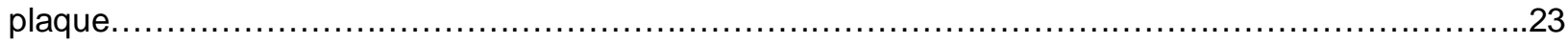

Figure 21. Predicted and measured second-order orientation tensor components (a) $A_{11}$ and (b) $A_{22}$ for

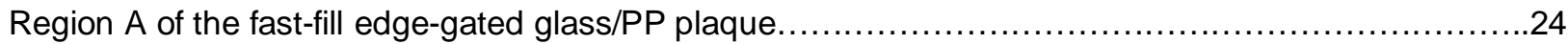

Figure 22. Predicted and measured second-order orientation tensor components (a) $A_{11}$ and (b) $A_{22}$ for

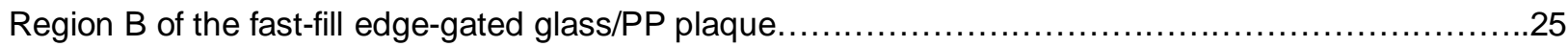

Figure 23. Predicted and measured second-order orientation tensor components (a) $A_{11}$ and (b) $A_{22}$ for Region $\mathrm{C}$ of the fast-fill edge-gated glass/PP plaque

Figure 24. Predicted and experimental weight-average lengths for the fast-fill edge-gated glass/PP

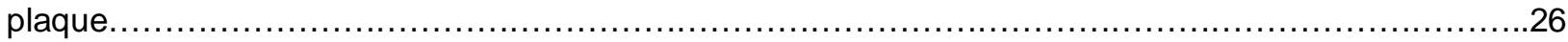

Figure 25. Predicted and measured second-order orientation tensor components (a) $A_{11}$ and (b) $A_{22}$ for

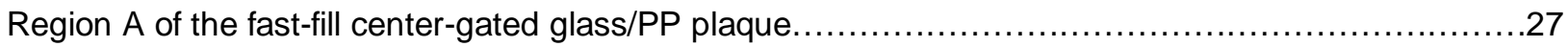

Figure 26. Predicted and measured second-order orientation tensor components (a) $A_{11}$ and (b) $A_{22}$ for

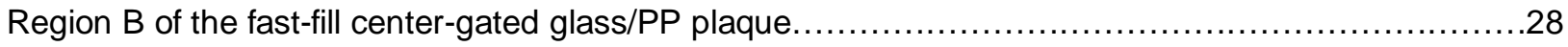
Figure 27. Predicted and measured second-order orientation tensor components (a) $A_{11}$ and (b) $A_{22}$ for

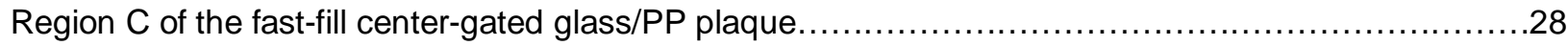


Figure 28. Predicted and experimental weight-average lengths for the fast-fill center-gated glass/PP

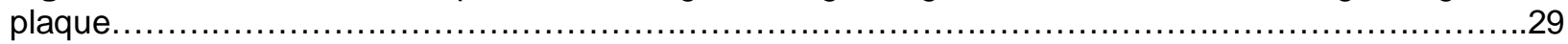

Figure 29. Predicted and measured second-order orientation tensor components (a) $A_{11}$ and (b) $A_{22}$ for

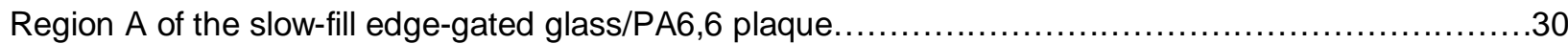
Figure 30. Predicted and measured second-order orientation tensor components (a) $A_{11}$ and (b) $A_{22}$ for

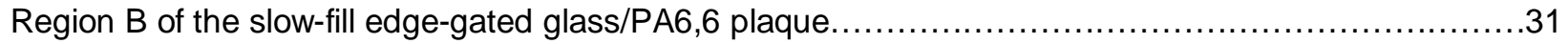
Figure 31. Predicted and measured second-order orientation tensor components (a) $A_{11}$ and (b) $A_{22}$ for Region $C$ of the slow-fill edge-gated glass/PA6,6 plaque ............................................... Figure 32. Predicted and experimental weight-average lengths for the slow-fill edge-gated glass/PA6, 6

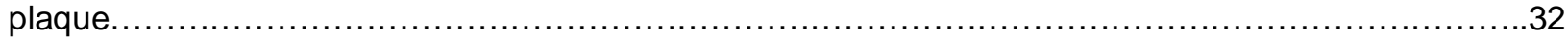

Figure 33. Predicted and measured second-order orientation tensor components (a) $A_{11}$ and (b) $A_{22}$ for

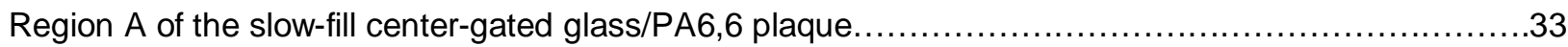

Figure 34. Predicted and measured second-order orientation tensor components (a) $A_{11}$ and (b) $A_{22}$ for

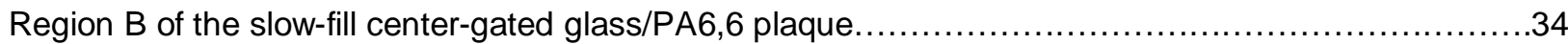

Figure 35. Predicted and measured second-order orientation tensor components (a) $A_{11}$ and (b) $A_{22}$ for

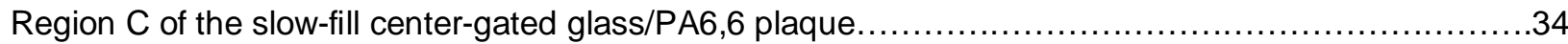
Figure 36. Predicted and experimental weight-average lengths for the slow-fill center-gated glass/PA6,6

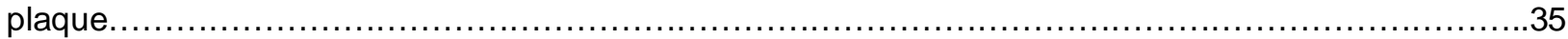

Figure 37. Predicted and measured second-order orientation tensor components (a) $A_{11}$ and (b) $A_{22}$ for

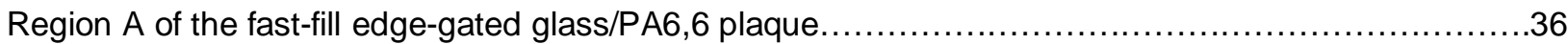
Figure 38. Predicted and measured second-order orientation tensor components (a) $A_{11}$ and (b) $A_{22}$ for

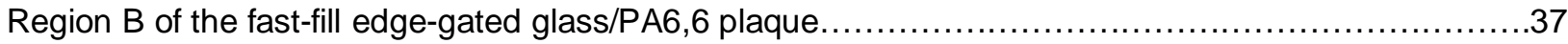
Figure 39. Predicted and measured second-order orientation tensor components (a) $A_{11}$ and (b) $A_{22}$ for

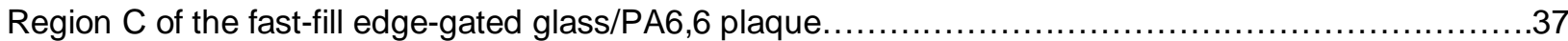
Figure 40. Predicted and experimental weight-average lengths for the fast-fill edge-gated glass/PA6,6 plaque..... ....38

Figure 41. Predicted and measured second-order orientation tensor components (a) $A_{11}$ and (b) $A_{22}$ for Region $A$ of the fast-fill center-gated glass/PA6,6 plaque ................................................ Figure 42. Predicted and measured second-order orientation tensor components (a) $A_{11}$ and (b) $A_{22}$ for Region $B$ of the fast-fill center-gated glass/PA6,6 plaque ................................................ 40 Figure 43. Predicted and measured second-order orientation tensor components (a) $A_{11}$ and (b) $A_{22}$ for

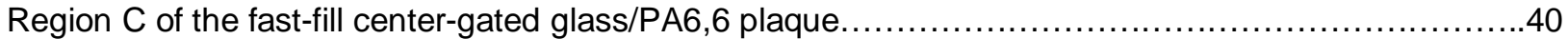
Figure 44. Predicted and experimental weight-average lengths for the fast-fill center-gated glass/PA6,6 plaque 


\section{List of Tables}

Table 1. Process parameters for the injection molding of the Dow Chemical DLGF9411.00 material......11 Table 2. Process parameters for the injection molding of the DuPont Zytel 75LG40HSL

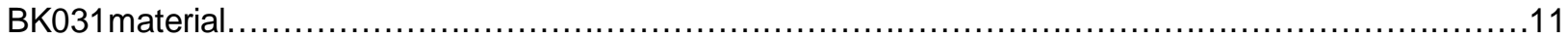

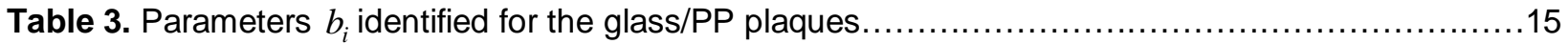

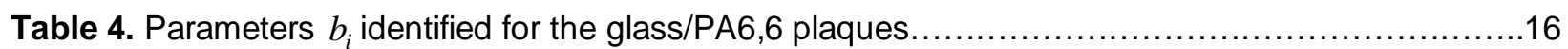

Table 5. Parameters RSC used in the AMI mid-plane and 3-D analyses of the ACC plaques.............16

Table 6. Fiber length model parameters used in the AMI mid-plane and 3-D analyses of the glass/PP

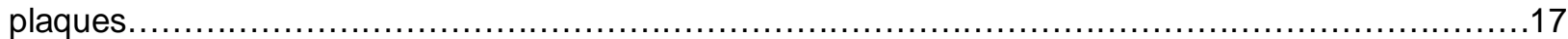

Table 7. Fiber length model parameters used in the AMI mid-plane and 3-D analyses of the glass/PA6,6

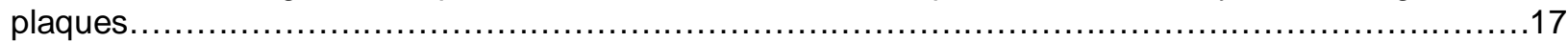

Table 8. Average values of $A_{11}$ in Regions $\mathrm{A}, \mathrm{B}$ and $\mathrm{C}$ of the slow-fill edge-gated glass/PP plaque.......20

Table 9. Weight-average lengths in Regions $A, B$ and $C$ of the slow-fill edge-gated glass/PP plaque.....20

Table 10. Average values of $A_{11}$ in Regions $A, B$ and $C$ of the slow-fill center-gated glass/PP plaque.....23

Table 11. Weight-average lengths in Regions $A, B$ and $C$ of the slow-fill center-gated glass/PP

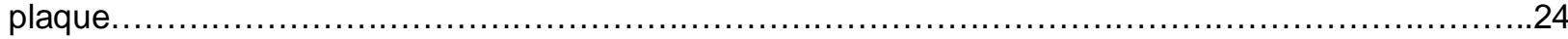

Table 12. Average values of $A_{11}$ in Regions $A, B$ and $C$ of the fast-fill edge-gated glass/PP plaque.......26

Table 13. Weight-average lengths in Regions $A, B$ and $C$ of the fast-fill edge-gated glass/PP plaque.....27

Table 14. Average values of $A_{11}$ in Regions $A, B$ and $C$ of the fast-fill center-gated glass/PP plaque.....22

Table 15. Weight-average lengths in Regions $A, B$ and $C$ of the fast-fill center-gated glass/PP

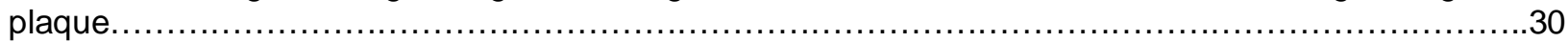

Table 16. Average values of $A_{11}$ in Regions $A, B$ and $C$ of the slow-fill edge-gated glass/PA6,6

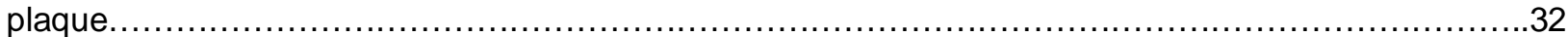

Table 17. Weight-average lengths in Regions A, B and C of the slow-fill edge-gated glass/PA6,6

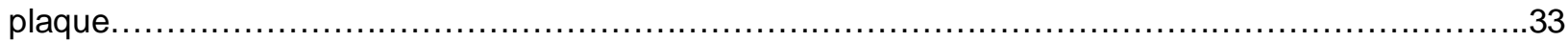

Table 18. Average values of $A_{11}$ in Regions $A, B$ and $C$ of the slow-fill center-gated glass/PA6,6

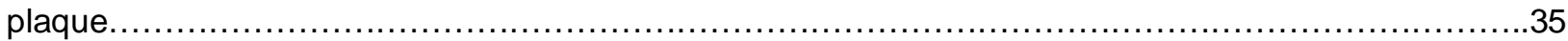

Table 19. Weight-average lengths in Regions A, B and C of the slow-fill center-gated glass/PA6,6

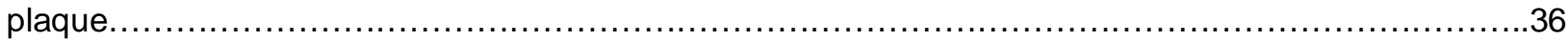

Table 20. Average values of $A_{11}$ in Regions $A, B$ and $C$ of the fast-fill edge-gated glass/PA6,6 plaque...38

Table 21. Weight-average lengths in Regions $A, B$ and $C$ of the fast-fill edge-gated glass/PA6,6

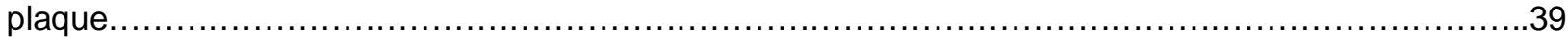

Table 22. Average values of $A_{11}$ in Regions $A, B$ and $C$ of the fast-fill center-gated glass/PA6,6

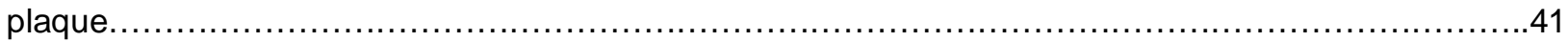
Table 23. Weight-average lengths in Regions A, B and C of the fast-fill center-gated glass/PA6,6 plaque. . .42 


\subsection{Introduction}

Under the previous CRADA (Nr. PNNL/260), Battelle PNNL had worked with the University of Illinois at Urbana-Champaign (UIUC) through subcontracts to develop advanced process models for fiber orientation and length distributions in injection-molded LFTs [1-3]. These models are the Phelps-Tucker anisotropic rotary diffusion - reduced strain closure (ARDRSC) model for predicting fiber orientation and the Phelps-Tucker fiber length attrition model. The models had been first implemented in an UIUC's in-house code named ORIENT for their preliminary validations and applications to small-size LFT samples. Next, Autodesk had implemented these models in Moldflow for the injection molding simulations of the same types of LFT samples. In addition, Autodesk, Inc. had performed rheological and mechanical tests to identify the rheological and physical properties for the pellet materials used in the CRADA. Both UIUC and Autodesk had provided Battelle PNNL with technical supports for the model validations.

This report describes the work conducted under the CRADA Nr. PNNL/304 between Battelle PNNL and Autodesk whose objective is to validate the new process models developed under the previous CRADA for large injection-molded LFT composite structures. To this end, the ARDRSC and fiber length attrition models implemented in the 2013 research version of Moldflow was used to simulate the injection molding of $600-\mathrm{mm} \times 600-\mathrm{mm} \times 3-\mathrm{mm}$ plaques from $40 \%$ glass/polypropylene (Dow Chemical DLGF9411.00) and 40\% glass/polyamide 6,6 (DuPont Zytel 75LG40HSL BK031) materials. The injection molding was performed by Injection Technologies, Inc. at Windsor, Ontario (under a subcontract by Oak Ridge National Laboratory, ORNL) using the mold offered by the Automotive Composite Consortium (ACC). Two fill speeds under the same back pressure were used to produce plaques under slow-fill and fast-fill conditions. Also, two gating options were used to achieve flows in edge-gated plaques and in center-gated plaques. After molding, ORNL performed measurements of fiber orientation and length distributions for process model validations.

The structure of this report is as follows. After the Introduction (Section 1), Section 2 provides a summary of the ARD-RSC and fiber length attrition models. A summary of model implementations in the latest research version of Moldflow is given in Section 3. Section 4 provides the key processing conditions and parameters for molding of the ACC plaques. The validations of the ARD-RSC and fiber length attrition models are presented and discussed in Section 5. The conclusions will be drawn in Section 6.

\subsection{Process Models Developed for LFTs}

\subsection{The Phelps-Tucker Anisotropic Rotary Diffusion - Reduced Strain Closure Model}

The Folgar-Tucker model accounts for fiber-fiber interactions through the isotropic rotary diffusion governed by the interaction coefficient $C_{I}$ [4]. Phelps and Tucker suggest that 
accounting for such interactions with the anisotropic rotary diffusion (ARD) should allow us to better capture the fiber orientation distribution in LFTs. Such a model then replaces the scalar $C_{\mathrm{I}}$ with a tensorial description $\mathbf{C}$ for the fiber-fiber interactions [3].

Previously, Phan-Thien et al. [5] proposed a fiber orientation model using anisotropic rotary diffusion. However, the Phan-Thien et al. model's diffusion term failed to return the fibers to an isotropic orientation at steady state, a necessary condition of any diffusion model. To correct the Phan-Thien et al. model, an expression for rotary diffusion was developed that was defined on the surface of the unit sphere traced by all orientations of the unit vector $\mathbf{p}$ [1-2]. The expression for the ARD model to properly match the LFT fiber orientation data is:

$$
\begin{gathered}
\dot{\mathbf{A}}=(\mathbf{W} \cdot \mathbf{A}-\mathbf{A} \cdot \mathbf{W})+\xi(\mathbf{D} \cdot \mathbf{A}+\mathbf{A} \cdot \mathbf{D}-2 \tilde{\mathbf{A}}: \mathbf{D}) \\
+\dot{\gamma}(2 \mathbf{C}-2(\operatorname{tr} \mathbf{C}) \mathbf{A}-5(\mathbf{C} \cdot \mathbf{A}+\mathbf{A} \cdot \mathbf{C})+10 \tilde{\mathbf{A}}: \mathbf{C})
\end{gathered}
$$

where $\mathbf{A}$ and $\tilde{\mathbf{A}}$ are the second- and fourth-order orientation tensors, respectively. $\dot{\mathbf{A}}=D \mathbf{A} / D t$ with $t$ being the time. $\mathbf{W}$ is the vorticity tensor, and $\mathbf{D}$ is the rate of the deformation tensor. $\dot{\gamma}$ is the scalar magnitude of $\mathbf{D}$, and $\xi$ is the shape parameter ( $\xi=1$ for any fiber). Tensor $\mathbf{C}$ is constructed from the $\mathbf{A}$ and $\mathbf{D}$ tensors as:

$$
\mathbf{C}=b_{1} \mathbf{I}+b_{2} \mathbf{A}+b_{3} \mathbf{A}^{2}+b_{4} \frac{\mathbf{D}}{\dot{\gamma}}+b_{5} \frac{\mathbf{D}^{2}}{\dot{\gamma}^{2}}
$$

where $b_{i}(i=1, . ., 5)$ are the scalar constants. A systematic method of selecting $b_{i}$ was developed in [1-2] to ensure stable and valid orientation solutions. To properly match experimental orientation data, it is necessary to slow the predicted orientation dynamics of the ARD model. For instance, the RSC model [6] can objectively slow the orientation dynamics of the Folgar-Tucker model. Treating the ARD model similarly, the ARD-RSC model is obtained as:

$$
\begin{aligned}
& \dot{\mathbf{A}}^{\mathrm{ARD}-\mathrm{RSC}}=(\mathbf{W} \cdot \mathbf{A}-\mathbf{A} \cdot \mathbf{W}) \\
& +\xi(\mathbf{D} \cdot \mathbf{A}+\mathbf{A} \cdot \mathbf{D}-2[\tilde{\mathbf{A}}+(1-\kappa)(\tilde{\mathbf{L}}-\tilde{\mathbf{M}}: \tilde{\mathbf{A}})]: \mathbf{D}) \\
& +\dot{\gamma}(2[\mathbf{C}-(1-\kappa) \tilde{\mathbf{M}}: \mathbf{C}]-2 \kappa(\operatorname{tr} \mathbf{C}) \mathbf{A} \\
& -5(\mathbf{C} \cdot \mathbf{A}+\mathbf{A} \cdot \mathbf{C})+10[\tilde{\mathbf{A}}+(1-\kappa)(\tilde{\mathbf{L}}-\tilde{\mathbf{M}}: \tilde{\mathbf{A}})]: \mathbf{C})
\end{aligned}
$$

where $\mathbf{C}$ is given by Equation (2). $\tilde{\mathbf{L}}$ and $\tilde{\mathbf{M}}$ are the fourth-order tensors that are defined in terms of the eigenvalues and eigenvectors of $\mathbf{A} . \kappa(<1)$ is a scalar parameter which controls the rate of orientation dynamics.

The ARD-RSC model was implemented in ORIENT and the research versions of Moldflow. It was then used in the injection-molding analyses of small-size glass-fiber/PP samples. The ORIENT and Moldflow fiber orientation predictions were discussed and compared to the experimental results in our previous CRADA report [3]. 


\subsection{The Phelps-Tucker Fiber Length Attrition Model}

Phelps and Tucker [2] have developed a fiber length attrition model to predict fiber length distribution in a mold cavity during injection molding. First, using a model by Dinh and Armstrong [7], an expression for the hydrodynamic force acting along the fiber axis is obtained. The condition for buckling that leads to fiber breakage compares this hydrodynamic force to the buckling force from the classical Euler buckling theory. This condition states that a fiber of length $l_{i}$ and orientation $\mathbf{p}$ will break if

$$
\frac{F_{i}(\mathbf{p})}{F_{\text {crit }}}=\left[\frac{4 \zeta \eta_{\mathrm{m}} l_{i}^{4}}{\pi^{3} E_{\mathrm{f}} d_{\mathrm{f}}^{4}}\right](-2 \mathbf{D}: \mathbf{p p})>1
$$

Here $F_{\text {crit }}$ is the critical compressive force based on the Euler buckling theory, $\zeta$ a dimensionless drag coefficient from the Dinh-Armstrong model, $\eta_{\mathrm{m}}$ the resin viscosity, $\mathbf{D}$ the rate of the deformation tensor, and $E_{\mathrm{f}}$ and $d_{\mathrm{f}}$ are the fiber elastic modulus and diameter, respectively.

Using criterion (4) in combination with typical orientation statistics of fibers, Phelps and Tucker express the probability that a fiber of length $l_{i}$ will break during a time increment $\Delta t$ as $P_{i} \Delta t$, where $P_{i}$ is given by

$$
P_{i}=C_{B} \dot{\gamma}\{1-\exp (1-\hat{\dot{\gamma}})\}
$$

where $C_{B}$ is a phenomenological coefficient that scales the breakage rate, and $\hat{\dot{\gamma}}$ is the expression in square brackets in Equation (4).

The local fiber length distribution is represented by a set of values $N_{i}, i=1$ to $n$, that give the number of fibers of length $l_{i}=i \Delta l$. Typically $n=130$ bins is used in the length distribution. As fibers break, this distribution must satisfy an equation expressing conservation of the total fiber length

$$
\frac{\partial N_{i}}{\partial t}+\mathbf{v} \bullet \nabla N_{i}=-P_{i} N_{i}+\sum_{k} R_{i k} N_{k}
$$

In this equation $R_{i k}$ is the rate of production of child fibers of length $l_{i}$ by breaking parents of length $l_{k}$ and $\mathbf{v}$ is the fluid velocity. $R_{i k}$ is determined by a combination of the parent breakage rate $P_{k}$ and the assumption that breaking points are distributed along the parent fiber length in a Gaussian profile. Together with Equations (4) and (5), this provides a full set of equations to solve for the fiber length distribution.

This fiber length attrition model was first implemented in ORIENT to enable fiber length predictions for injection molded LFT parts. ORIENT provides local values of viscosity, velocity and shear rate. Each node in the filling mesh has a length distribution (a set of $N_{i}$ values). The fiber length distribution is carried along with the polymer as it fills the mold cavity, and changes 
as the fibers break in response to the local shear rate. The measured fiber length distribution just inside the gate is used as an initial condition, and the model predicts the length distribution at all downstream locations.

\subsection{Summary of New Process Models Implementations}

The ARD-RSC and fiber length attrition models were implemented in the research versions of Moldflow. The model implementations were described in detail in our PNNL/260 CRADA report. This section only summarizes some key options for using these models. Some of these options do not exist in commercial releases.

\subsection{Dialog Box Designs for the ARD-RSC Model}

The ARD-RSC model was implemented in both the mid-plane/dual domain and threedimensional (3-D) modeling research versions of Moldflow. In the 2013 3-D modeling version, users can directly introduce the $b_{i}$ parameters (Eq. (2)) in a similar way to the options offered in the mid-plane/dual domain version. Figure 1 shows the dialog boxes to introduce the parameters of the ARD-RSC model (reduced strain closure factor, RSC, parameter $\kappa$ in Eq. (3), and parameters, $b_{i}$.

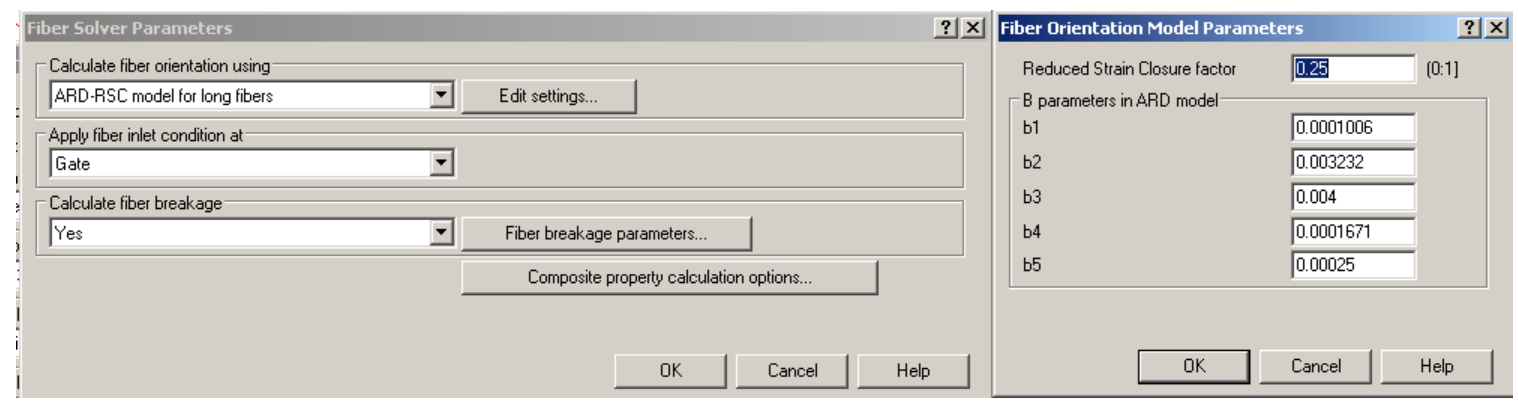

Figure 1. Dialog boxes for introducing parameters of the ARD-RSC model

\subsection{Dialog Box Designs for the Fiber Length Attrition Model}

First of all, a long fiber filled polymer material must be selected for fiber breakage calculation. The threshold for "long" fiber is 1 millimeter $(\mathrm{mm})$. The fiber breakage calculation is carried out above this threshold. The dialog box for a long fiber filled material can be found under "Filler Properties" of Thermoplastics material dialog box as shown below and marked by the red circle (Figure 2): 


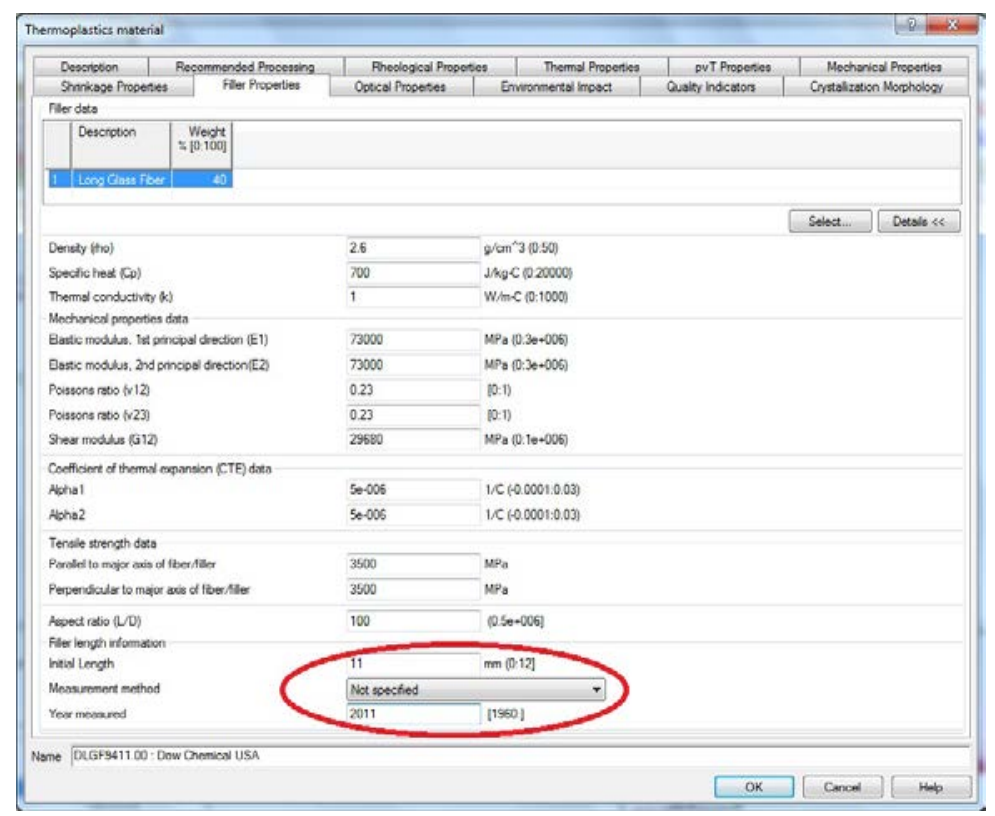

Figure 2. Dialog box for selecting fiber breakage calculation for a long fiber material

Figure 3 shows the dialog box for fiber solver parameters that includes the fiber breakage model parameters and inlet/output control. By clicking on "Fiber breakage parameters", the dialog box for these parameters shown in Figure 4 pops up:

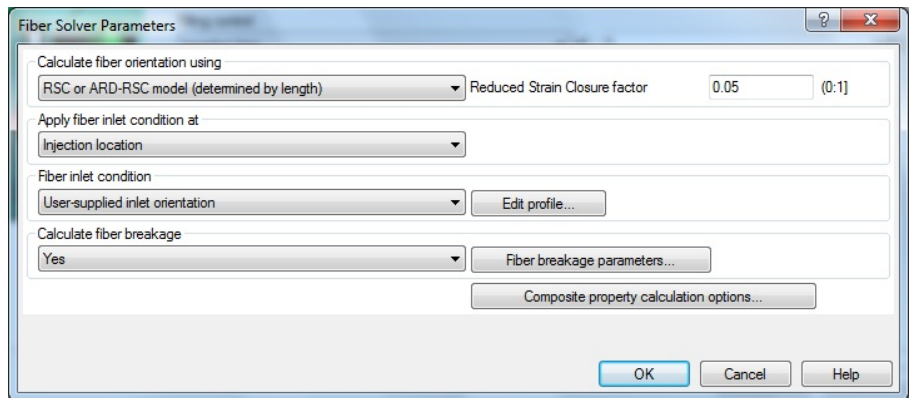

Figure 3. Dialog box for fiber solver parameters

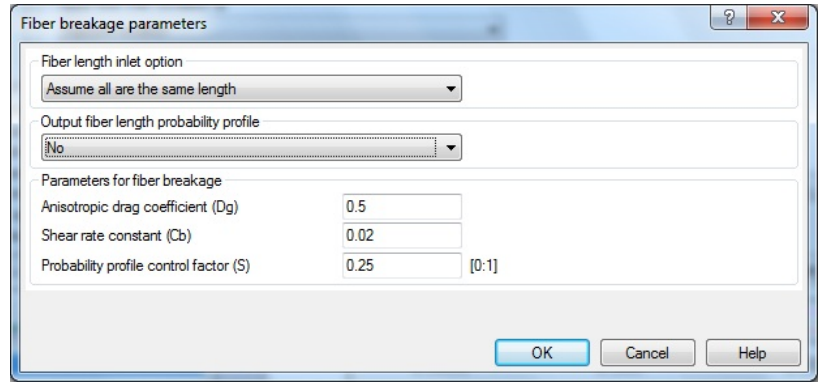

Figure 4. Dialog box for fiber breakage parameters 
Alternatively, the option "Use a length distribution" can be selected (Figure 5). This fiber length inlet condition is, in particular, designed for a user who may have the knowledge about the length breakage in the nozzle. In this case, a length profile can be introduced as illustrated in Figure 6.

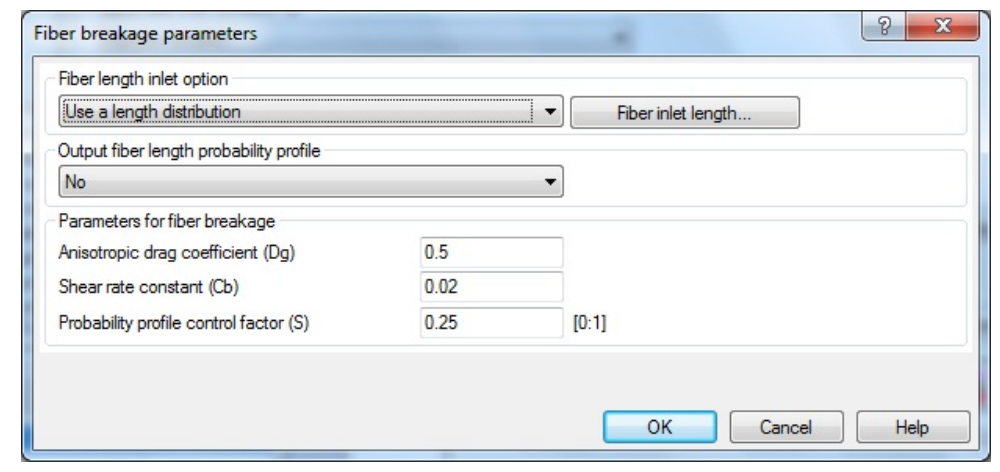

Figure 5. Dialog box for fiber breakage parameters: use of a length distribution

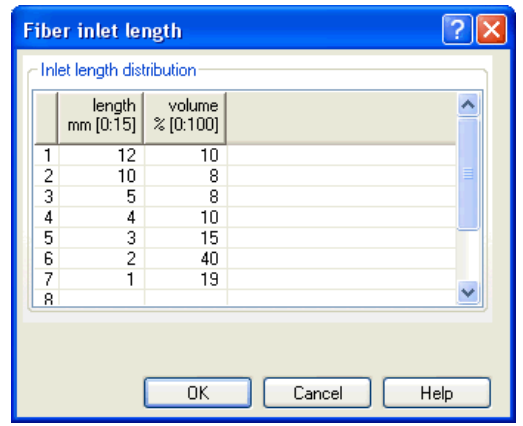

Figure 6. Dialog box for inlet length distributions

\subsection{Processing Conditions and Parameters}

Injection molding of $600-\mathrm{mm} \quad \mathrm{x} \quad 600-\mathrm{mm} \quad \mathrm{x}$ 3-mm square plaques from $40 \%$ glass/polypropylene (PP) (Dow Chemical DLGF9411.00) and 40\% glass/polyamide 6,6 (PA6,6) (DuPont Zytel 75LG40HSL BK031) pellets was performed by Injection Technologies, Inc. at Windsor, Ontario (under a subcontract by ORNL) using the mold offered by the Automotive Composite Consortium (ACC). Two fill speeds under the same back pressure were used to produce plaques under slow-fill and fast-fill conditions. Also, two gating options were used to achieve the following desired flow patterns: flows in edge- gated plaques and in center-gated plaques. The rheological and physical properties of the above materials were previously identified by Autodesk and exist in the material data base of Moldflow. Tables 1 and 2 gather the key process parameters for molding these materials. 


\begin{tabular}{|ccccc|}
\hline $\begin{array}{c}\text { Process } \\
\text { Parameters }\end{array}$ & $\begin{array}{c}\text { Slow-fill edge- } \\
\text { gated plaque }\end{array}$ & $\begin{array}{c}\text { Slow-fill center- } \\
\text { gated plaque }\end{array}$ & $\begin{array}{c}\text { Fast-fill edge- } \\
\text { gated plaque }\end{array}$ & $\begin{array}{c}\text { Fast-fill center- } \\
\text { gated plaque }\end{array}$ \\
\hline $\begin{array}{c}\text { Injection time } \\
(\mathrm{s})\end{array}$ & 6.41 & 5.35 & 3.02 & 2.73 \\
$\begin{array}{c}\text { Mold-surface } \\
\text { temperature }\left({ }^{\circ} \mathrm{C}\right)\end{array}$ & 38 & 38 & 38 & 38 \\
$\begin{array}{c}\text { Melt temperature } \\
\left({ }^{\circ} \mathrm{C}\right)\end{array}$ & 265.55 & 265.55 & 265.55 & 265.55 \\
$\begin{array}{c}\text { Cooling time } \\
(\mathrm{s})\end{array}$ & 25 & 25 & 25 & 25 \\
\hline
\end{tabular}

Table 1. Process parameters for the injection molding of the Dow Chemical DLGF9411.00 material

\begin{tabular}{|ccccc|}
\hline $\begin{array}{c}\text { Process } \\
\text { Parameters }\end{array}$ & $\begin{array}{c}\text { Slow-fill edge- } \\
\text { gated plaque }\end{array}$ & $\begin{array}{c}\text { Slow-fill center- } \\
\text { gated plaque }\end{array}$ & $\begin{array}{c}\text { Fast-fill edge- } \\
\text { gated plaque }\end{array}$ & $\begin{array}{c}\text { Fast-fill center- } \\
\text { gated plaque }\end{array}$ \\
\hline $\begin{array}{c}\text { Injection time } \\
(\mathrm{s})\end{array}$ & 5.72 & 4.56 & 3.07 & 2.47 \\
$\begin{array}{c}\text { Mold-surface } \\
\text { temperature }\left({ }^{\circ} \mathrm{C}\right)\end{array}$ & 100 & 100 & 100 & 100 \\
$\begin{array}{c}\text { Melt temperature } \\
\left({ }^{\circ} \mathrm{C}\right)\end{array}$ & 310 & 310 & 310 & 310 \\
$\begin{array}{c}\text { Cooling time } \\
(\mathrm{s})\end{array}$ & 25 & 25 & 25 & 25 \\
\hline
\end{tabular}

Table 2. Process parameters for the injection molding of the DuPont Zytel 75LG4OHSL BK031material

\subsection{AMI Analyses of ACC Plaques}

This section describes the Moldflow analyses for all the ACC plaques molded using the above-mentioned Dow Chemical glass/PP and DuPont glass/PA6,6 materials. The CAD files for the geometries of the ACC plaques were received from the Automotive Composite Consortium. From the CAD files, the Moldflow mi-plane (2.5) and 3-D models for these plaques were built using the triangular multilayer elements and the three-dimensional tetrahedral elements of Moldflow, respectively. The feeding systems are modeled using the beam elements of Moldflow. Figures 7 and 8 show the Moldflow mi-plane models for the edge-gated plaques (7278 20-layer mid-plane elements) and center-gated plaques (5881 20-layer mid-plane elements), respectively. 
The 3-D models for the edge-gated plaques (347364 tetrahedral elements) and the center-gated plaques (270627 tetrahedral elements) are given in Figures 9 and 10, respectively. In the 3-D models, the through-thickness finite element discretizations capture 12 layers.

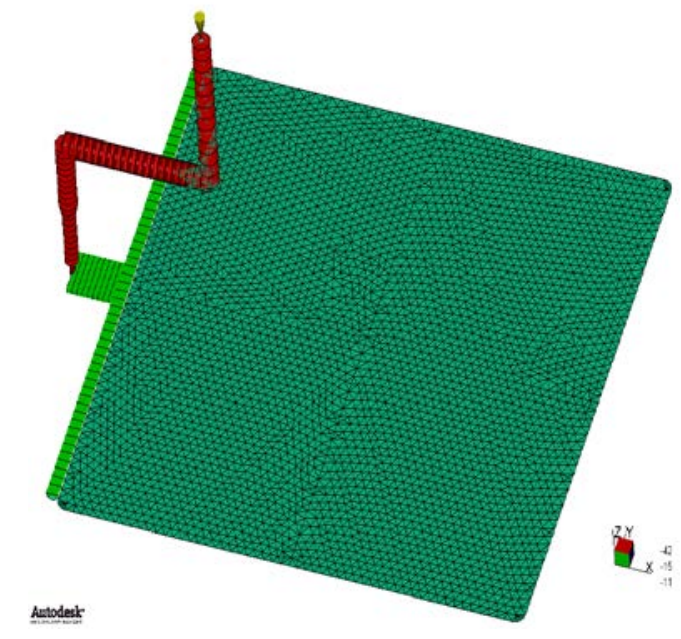

Figure 7. The AMI mid-plane model for the injection molding analyses of the ACC edge-gated plaques the feeding system and gate are modeled with beam elements

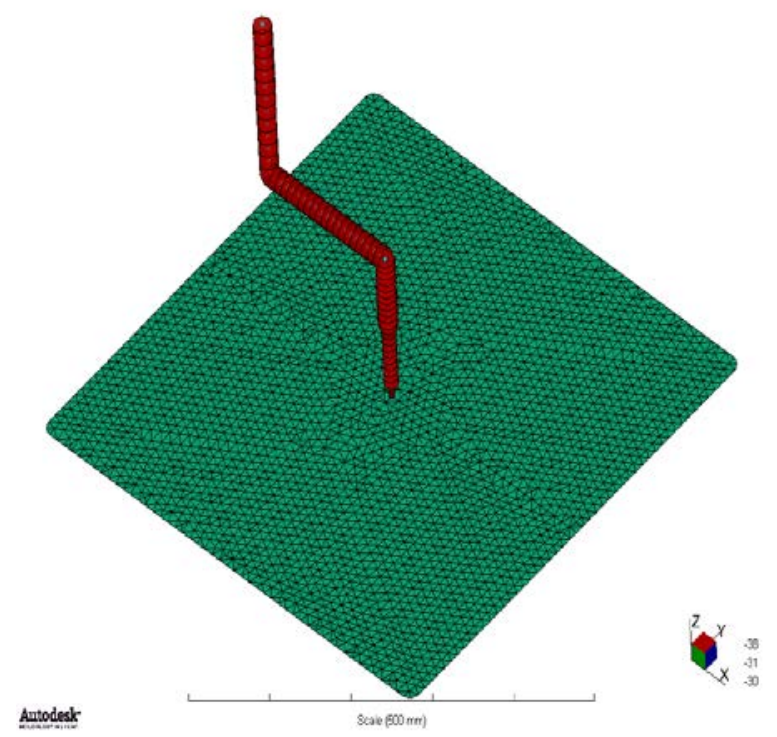

Figure 8. The AMI mid-plane model for the injection molding analyses of the ACC center-gated plaques 


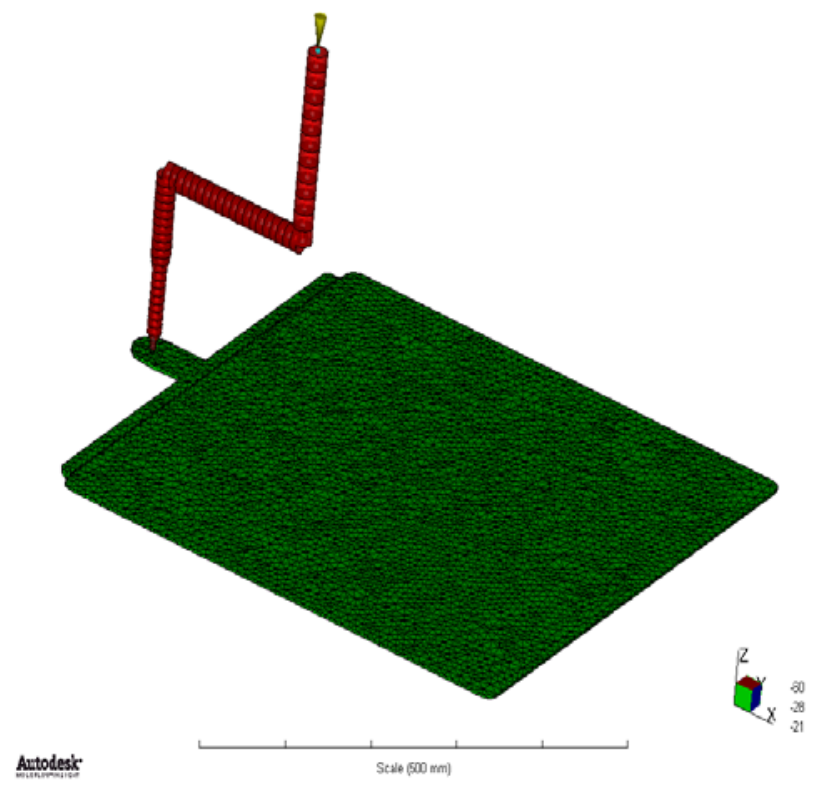

Figure 9. The AMI 3-D model for the injection molding analyses of the ACC edge-gated plaques

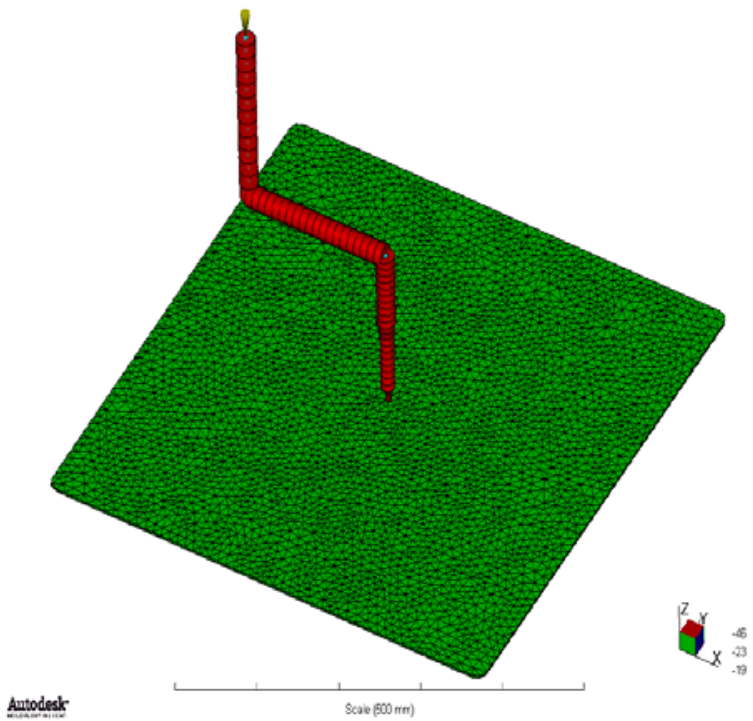

Figure 10. The AMI 3-D model for the injection molding analyses of the ACC center-gated plaques

Three regions on the plaques were considered for fiber length and orientation measurements. They are denoted as "Region A", "Region B", and "Region C" and are located on a center line at $38 \mathrm{~mm}, 140 \mathrm{~mm}$, and $241 \mathrm{~mm}$ from the injection location of the center-gated plaques (Figure 11). These regions are located on the centerline at $38 \mathrm{~mm}, 165 \mathrm{~mm}$, and $444.5 \mathrm{~mm}$ from the gate of the edge-gated plaques (Figure 12). The model validations were performed by comparing the predicted fiber orientation and length distributions with the corresponding experimental results determined for these regions. The Predictive Engineering project steering committee and US 
DOE Office of Vehicle Technologies requested to assess the model predictions based on the 15\% accuracy criterion.

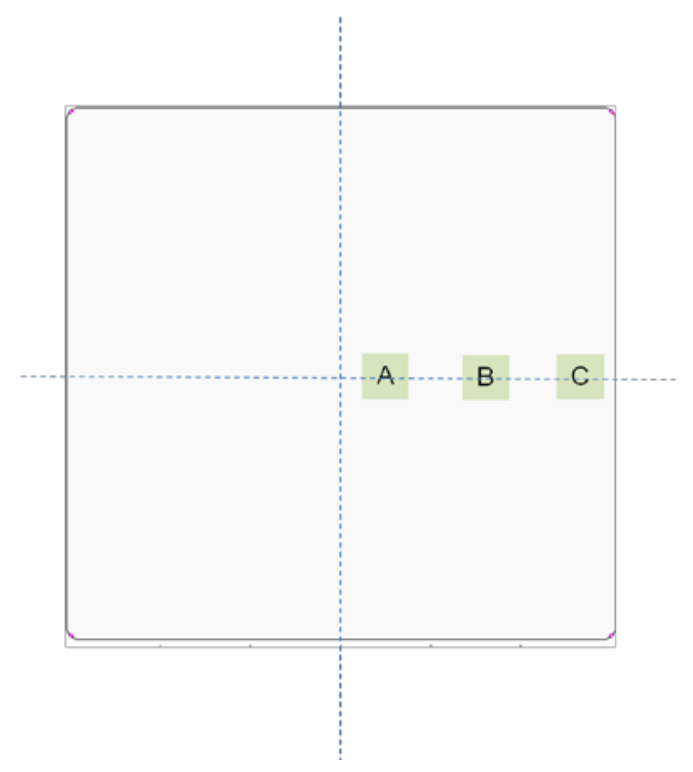

Figure 11. Regions A, B and C being $25.4 \mathrm{~mm}$ long along a centerline at $38 \mathrm{~mm}, 140 \mathrm{~mm}$, and $241 \mathrm{~mm}$ from the injection locations of the ACC center-gated plaques were taken for fiber length and orientation measurements

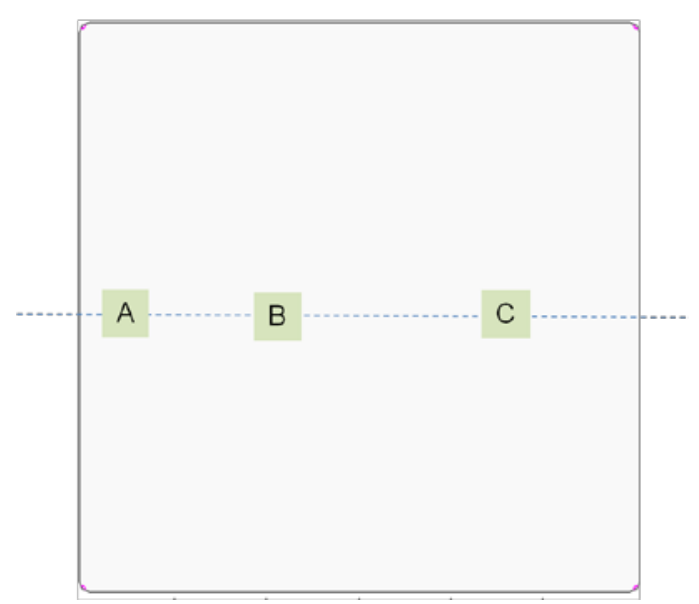

Figure 12. Regions $A, B$ and $C$ being $25.4 \mathrm{~mm}$ long along the centerline at $38 \mathrm{~mm}, 140 \mathrm{~mm}$, and $241 \mathrm{~mm}$ from the gate of the ACC edge-gated plaques were taken for fiber length and orientation measurements

\subsection{Identification of the ARD-RSC Model Parameters}

The ARD-RSC model contains a set of material parameters ( $b_{i}$ and RSC parameters) which can be identified using a target orientation state [1]. In principle, the target orientation state in the 
steady simple shear flow is chosen for the identification. Flow in an edge-gated plaque is representative of a steady simple shear flow; and therefore, the identification procedure uses the average fiber orientation components in the shell layers of an edge-gated plaque near the gate region to identify the parameters of the ARD-RSC model. A careful selection of the five parameters $b_{i}$ is crucial in order to obtain accurate and stable fiber orientation solution. A valid set of parameters $b_{i}$ must satisfy the criteria proposed in [1] and must give a solution to either the ARD or ARD-RSC model in which

- the steady, simple shear flow solution is equal to the target orientation tensor,

- the steady, simple shear flow solution is linearly stable,

- the $\mathbf{C}$ tensor has positive eigenvalues at all times in all flows, and

- the transient solution is physically valid in simple shear, as well as planar, uniaxial, and biaxial elongation flows.

Examining the orientation tensor components $A_{11}$ and $A_{22}$ measured in the shell layers near the gates in the edge-gated and center-gated plaques of the present moldings has revealed that the $A_{11}$ values in the edge-gated plaques are significantly higher than the $A_{11}$ values in the centergated plaques. As a result, a compromise target orientation state based on the target orientation values of $A_{11}$ and $A_{22}$ in both the edge-gated and center-gated plaques was adopted to identify the $b_{i}$ parameters for a given molded material. Tables 3 and 4 provide the $b_{i}$ parameters identified by this procedure for the plaques molded from both materials studied in this work. A value of the reduced strain closure factor RSC was first adopted for the identification process of $b_{i}$, however, it was adjusted through AMI analyses of the plaques so that the predicted fiber orientation distributions at selected regions match the experimental results. Table 5 presents the final RSC values used in the AMI mid-plane and 3-D analyses of the ACC glass/PP and glass/PA6,6 plaques.

\begin{tabular}{|cc|}
\hline Parameter & \\
\hline$b_{1}$ & $1.006 \mathrm{E}-4$ \\
$b_{2}$ & $3.232 \mathrm{E}-3$ \\
$b_{3}$ & $4 \mathrm{E}-3$ \\
$b_{4}$ & $1.671 \mathrm{E}-3$ \\
$b_{5}$ & $2.5 \mathrm{E}-4$ \\
\hline
\end{tabular}

Table 3. Parameters $b_{i}$ identified for the glass/PP plaques 


\begin{tabular}{|cc|}
\hline Parameter & \\
\hline$b_{1}$ & $1.762 \mathrm{E}-4$ \\
$b_{2}$ & $1.504 \mathrm{E}-3$ \\
$b_{3}$ & 0.007 \\
$b_{4}$ & $2.073 \mathrm{E}-4$ \\
$b_{5}$ & 0 \\
\hline
\end{tabular}

Table 4. Parameters $b_{i}$ identified for the glass/PA6,6 plaques

\begin{tabular}{|lcc|}
\hline Gating Conditions & RSC (Glass/PP Plaques) & RSC (Glass/PA6,6 Plaques) \\
\hline Edge-gated (mid-plane) & 0.25 & 0.35 \\
Edge-gated (3-D) & 0.25 & 0.1 \\
Center-gated (mid-plane) & 0.25 & 0.35 \\
Center-gated (3-D) & 0.25 & 0.1 \\
\hline
\end{tabular}

Table 5. Parameters RSC used in the AMI mid-plane and 3-D analyses of the ACC plaques

\subsection{Identification of the Fiber Length Attrition Model Parameters}

At this stage there does not exist a systematic method for the identification of the fiber length model parameters. Therefore, we have carried out the identification of these parameters through the injection-molding simulations of the plaques. Limited data for fiber length distributions in the nozzles are available for four plaques. The weight-average lengths in the nozzle for these cases have guided to adopt the uniform inlet length values prescribed at gate for the Moldflow analyses. Tables 6 and 7 give the values of the length model parameters used in the analyses of the glass/PP and glass/PA6,6, respectively. 


\begin{tabular}{|lcccc|}
\hline Gating Conditions & $\mathrm{D}_{\mathrm{g}}$ & $\mathrm{C}_{\mathrm{b}}$ & $\mathrm{S}$ & Inlet Length (mm) \\
\hline Edge-gated (mid-plane) & 0.1 & 0.0015 & 0.75 & 1.75 \\
Edge-gated (3-D) & 0.25 & $2.5 \mathrm{E}-4$ (fast-fill) & 0.75 & 1.75 \\
& & $7 \mathrm{E}-4$ (slow-fill) & & \\
Center-gated (mid-plane) & 0.1 & 0.005 & 0.75 & 1.5 (fast-fill) \\
& & & & 1.75 (slow-fill) \\
Center-gated (3-D) & 0.1 & $5 \mathrm{E}-5$ & 0.75 & 1.5 (fast-fill) \\
& & & & 1.75 (slow-fill) \\
\hline
\end{tabular}

Table 6. Fiber length model parameters used in the AMI mid-plane and 3-D analyses of the glass/PP plaques

\begin{tabular}{|lcccc|}
\hline Gating Conditions & $\mathrm{D}_{\mathrm{g}}$ & $\mathrm{C}_{\mathrm{b}}$ & $\mathrm{S}$ & Inlet Length (mm) \\
\hline Edge-gated (mid-plane) & 0.5 & 0.002 & 0.25 & 1.5 \\
Edge-gated (3-D) & 0.25 & 0.001 & 0.75 & 1.5 \\
Center-gated (mid-plane) & 0.25 & 0.009 & 0.75 & 1.75 (slow-fill) \\
& & & & 1.5 (fast-fill) \\
Center-gated (3-D) & 0.25 & $1 \mathrm{E}-4$ & 0.75 & 1.75 (slow-fill) \\
& & & & 1.5 (fast-fill) \\
\hline
\end{tabular}

Table 7. Fiber length model parameters used in the AMI mid-plane and 3-D analyses of the glass/PA6,6 plaques

\subsection{Fiber Orientation and Length Results for the Dow Chemical Glass/PP Plaques}

The fiber orientation results in terms of the second-order orientation tensor components $A_{11}$ and $A_{22}$ in the flow and cross-flow directions for the slow-fill edge-gated glass/PP plaque at Regions A, B and C are presented in Figures 13 to 15. These results show that the mid-plane model provides accurate predictions for all the regions while the 3-D model can reasonably well 
predict fiber orientation only in the shell layers. Figure 16 illustrates the weight-average lengths predicted for this plaque and compared to the experimental results. The mid-plane model's results agree with the experimental weight-average lengths in Regions A and B while the 3-D model provides better predictions in trend and values from Regions A to C.

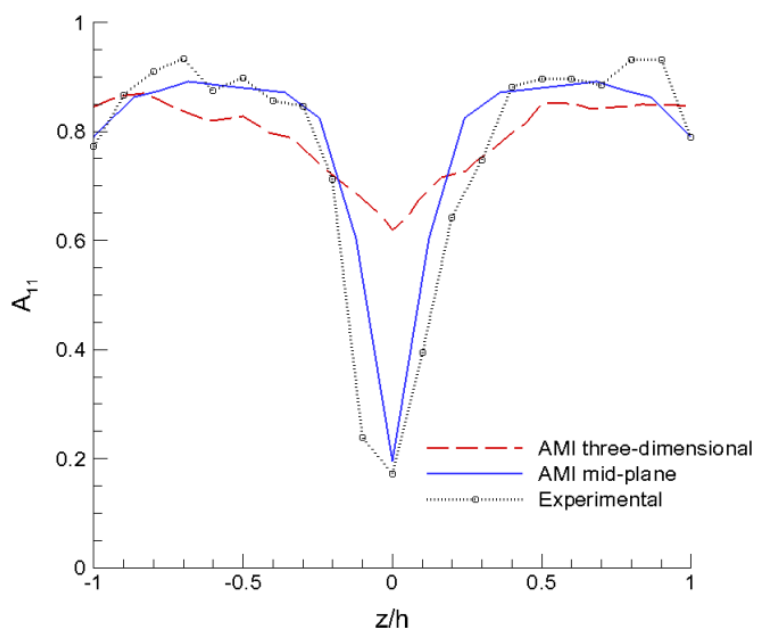

(a)

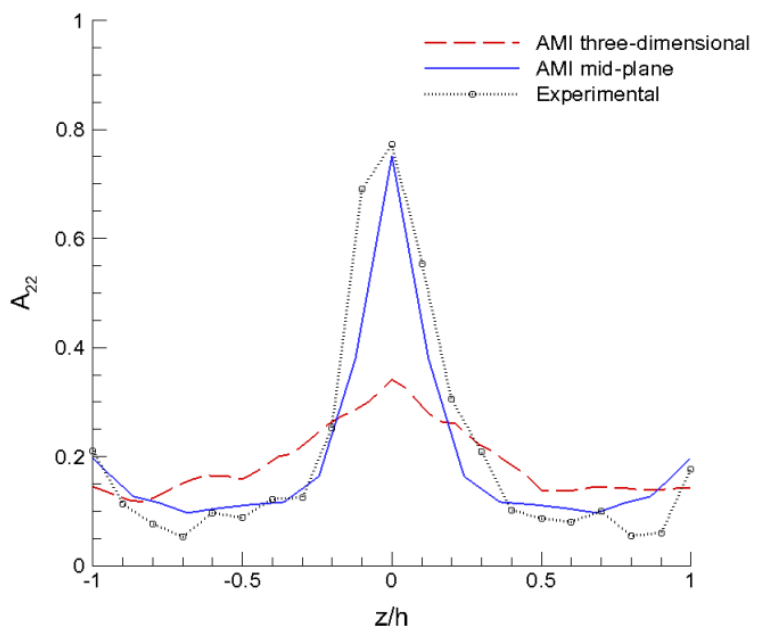

(b)

Figure 13. Predicted and measured second-order orientation tensor components (a) $A_{11}$ and (b) $A_{22}$ for Region A of the slow-fill edge-gated glass/PP plaque

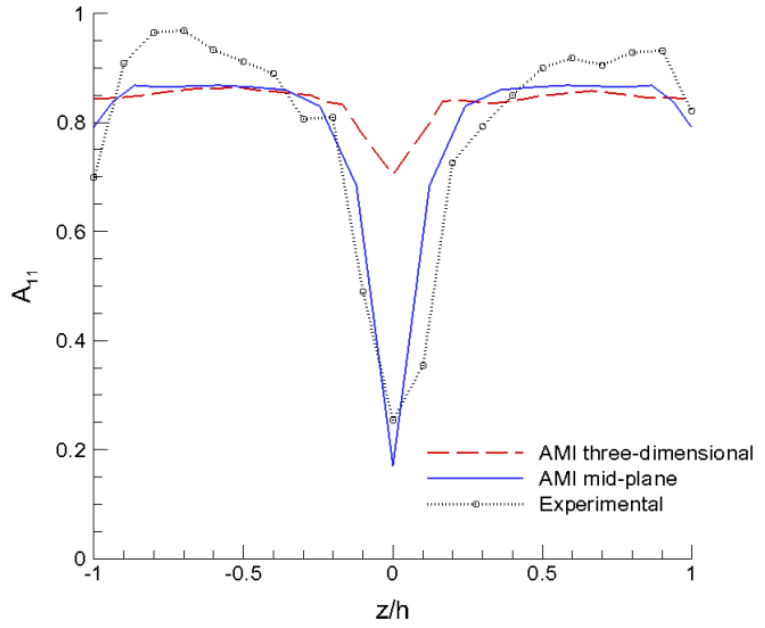

(a)

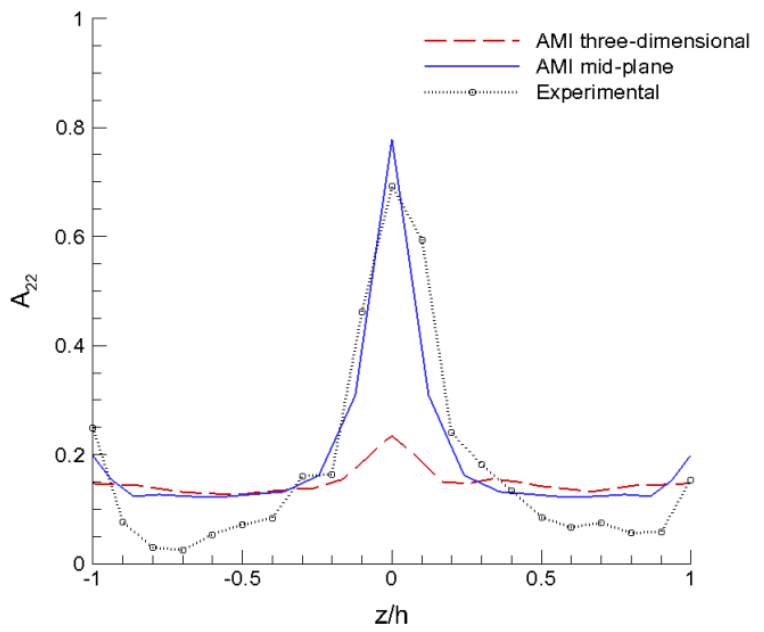

(b)

Figure 14. Predicted and measured second-order orientation tensor components (a) $A_{11}$ and (b) $A_{22}$ for Region B of the slow-fill edge-gated glass/PP plaque 


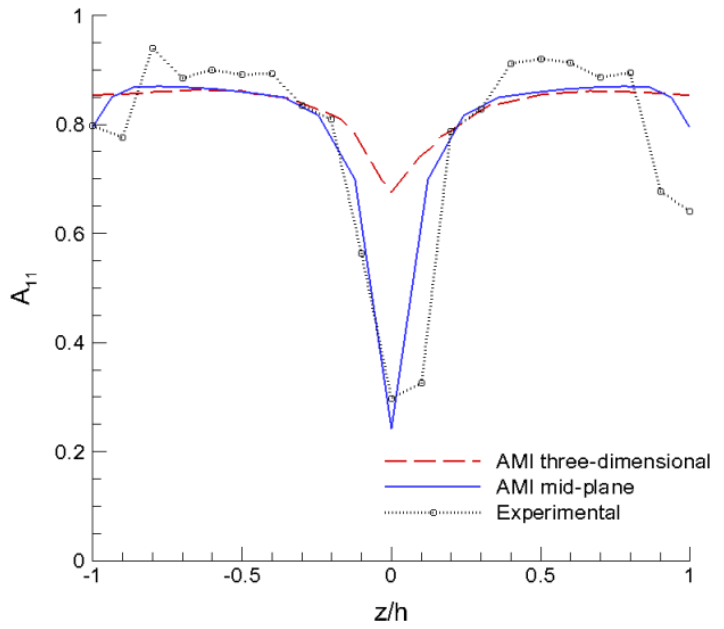

(a)

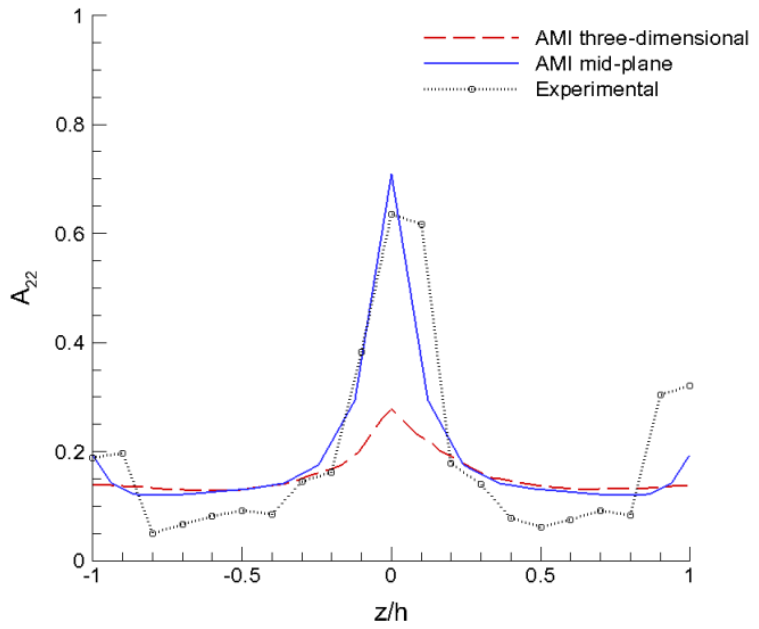

(b)

Figure 15. Predicted and measured second-order orientation tensor components (a) $A_{11}$ and (b) $A_{22}$ for Region C of the slow-fill edge-gated glass/PP plaque

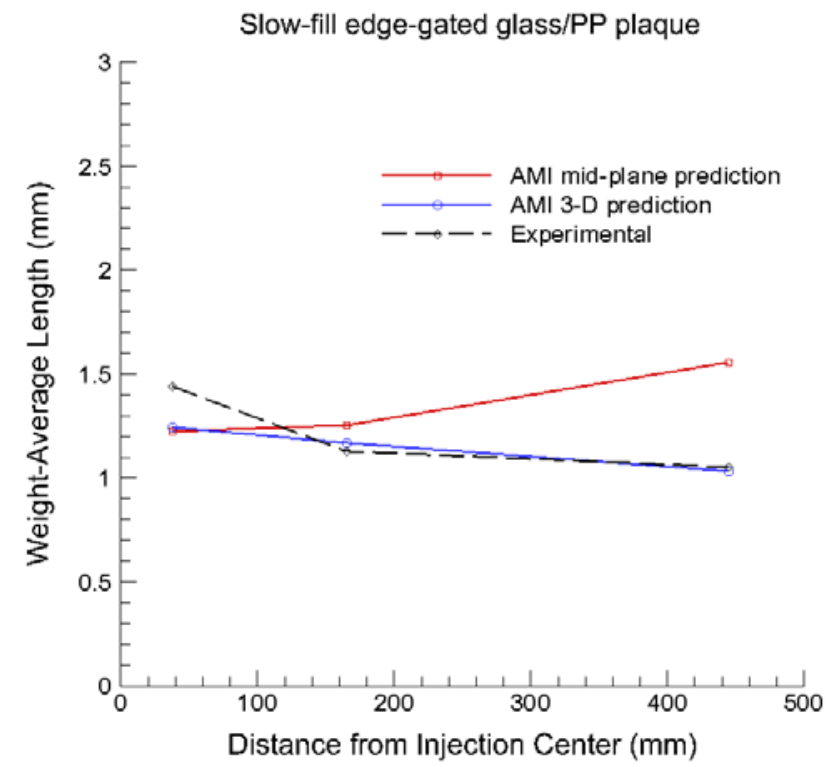

Figure 16. Predicted and experimental weight-average lengths for the slow-fill edge-gated glass/PP plaque 
For an overall assessment of the prediction accuracy, the average values of the predicted fiber orientation tensor component $A_{11}$ and the weight-average lengths at the selected regions are compared to the corresponding experimental results based on the $15 \%$ accuracy criterion. The overall assessments of fiber length and orientation predictions for the slow-fill edge-gated glass/PP plaque are summarized in Tables 8 and 9, respectively. The percentages within which the predictions agree with the experimental average values are also provided in these tables. The predicted values are marked "red" if they are above the $15 \%$ range.

\begin{tabular}{|c|c|c|c|}
\hline \multicolumn{5}{|c|}{ Region A } \\
\hline \multirow{2}{*}{ Average value } & Experimental & AMI mid-plane & AMI 3-D \\
\hline$A_{11}$ & 0.7654 & $0.8(4.6 \%)$ & $0.7931(3.6 \%)$ \\
\hline \multicolumn{5}{|c|}{ Region B } \\
\hline Average value & Experimental & AMI mid-plane & AMI 3-D \\
\hline$A_{11}$ & 0.7981 & $0.8015(0.5 \%)$ & $0.8362(4.8 \%)$ \\
\hline \multicolumn{2}{|c|}{ Region C } \\
\hline$A_{11}$ & Experimental & AMI mid-plane & AMI 3-D \\
\hline
\end{tabular}

Table 8. Average values of $A_{11}$ in Regions $A, B$ and $C$ of the slow-fill edge-gated glass/PP plaque

\begin{tabular}{|c|c|c|c|}
\hline $\begin{array}{c}\text { Weight-Average } \\
\text { Length }(\mathbf{m m})\end{array}$ & Region A & Region B & Region C \\
\hline AMI mid-plane & $1.224(14.9 \%)$ & $1.252(11.1 \%)$ & $1.55(47.6 \%)$ \\
\hline AMI 3-D & $1.24(13.9 \%)$ & $1.17(3.5 \%)$ & $1.03(1.9 \%)$ \\
\hline Experimental & 1.438 & 1.127 & 1.05 \\
\hline
\end{tabular}

Table 9. Weight-average lengths in Regions A, B and C of the slow-fill edge-gated glass/PP plaque

The fiber orientation results for slow-fill center-gated glass/PP plaque at the as-defined regions are given in Figures 17 to 19 while the weight-average length results for this plaque at 
the same regions are presented on Figure 20. There are the same findings as for the previous plaque regarding the comparison with the experimental results: the mid-plane model accurately predicts fiber orientation in all three regions while the 3-D model can only capture the shell layers accurately. However, the 3-D model can fairly predict the slight asymmetry in orientation with respect to the plaque mid-plane. Figure 20 shows that the predicted weight-average lengths by both the mid-plane and 3-D models agree well with the experimental results in Regions $\mathrm{A}$ and $\mathrm{C}$ while the experimental weight-average length in Region B is too high and is out of the observed range. The overall assessments (based on the 15\% accuracy criterion) of fiber length and orientation predictions for the slow-fill center-gated glass/PP plaque are summarized in Tables 10 and 11, respectively.

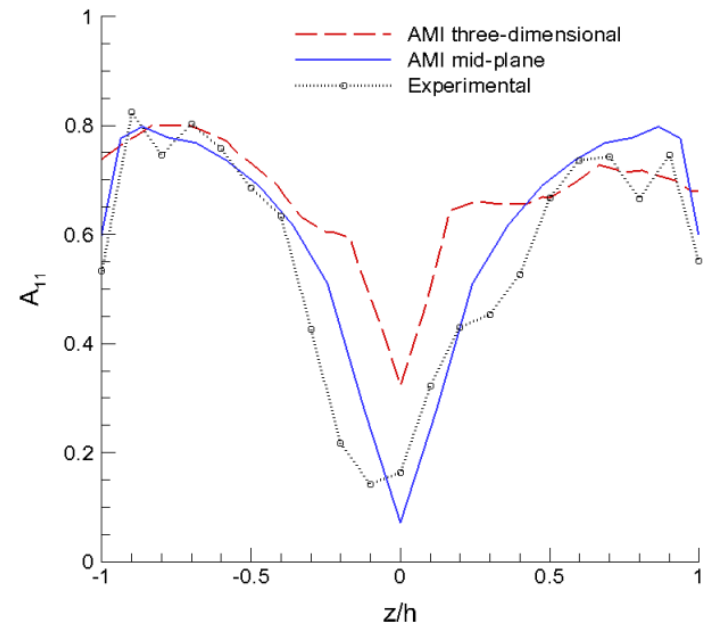

(a)

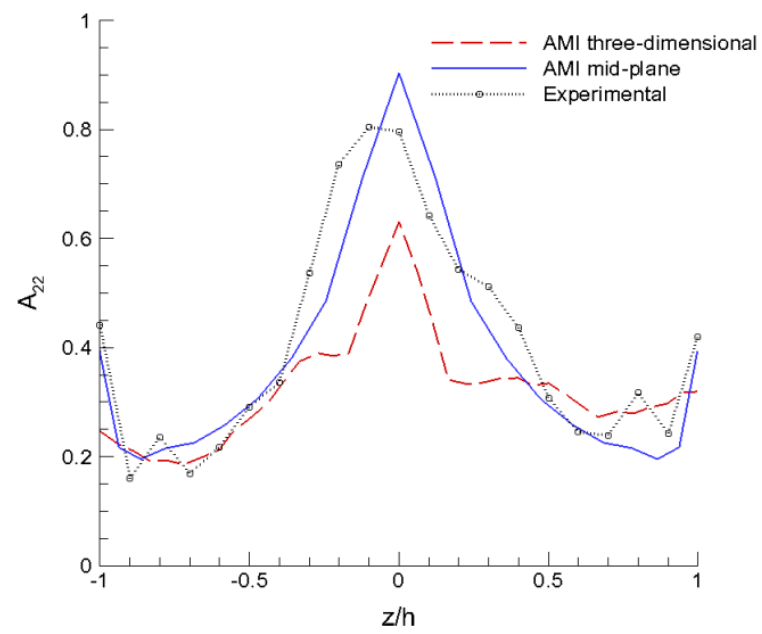

(b)

Figure 17. Predicted and measured second-order orientation tensor components (a) $A_{11}$ and (b) $A_{22}$ for Region A of the slow-fill center-gated glass/PP plaque 


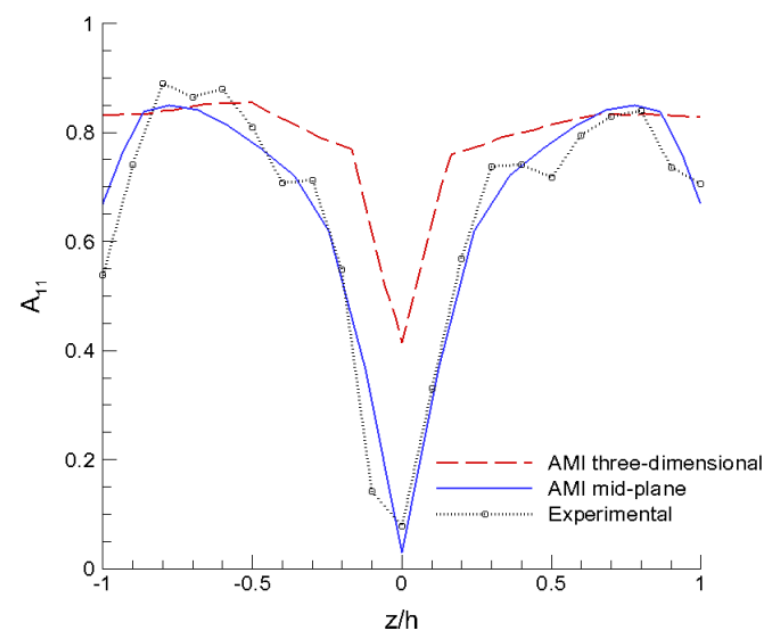

(a)

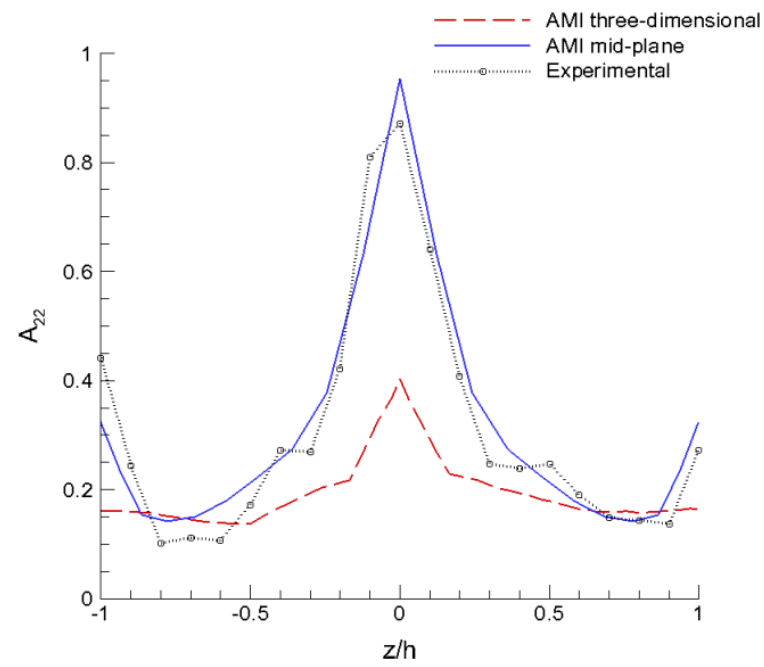

(b)

Figure 18. Predicted and measured second-order orientation tensor components (a) $A_{11}$ and (b) $A_{22}$ for Region B of the slow-fill center-gated glass/PP plaque

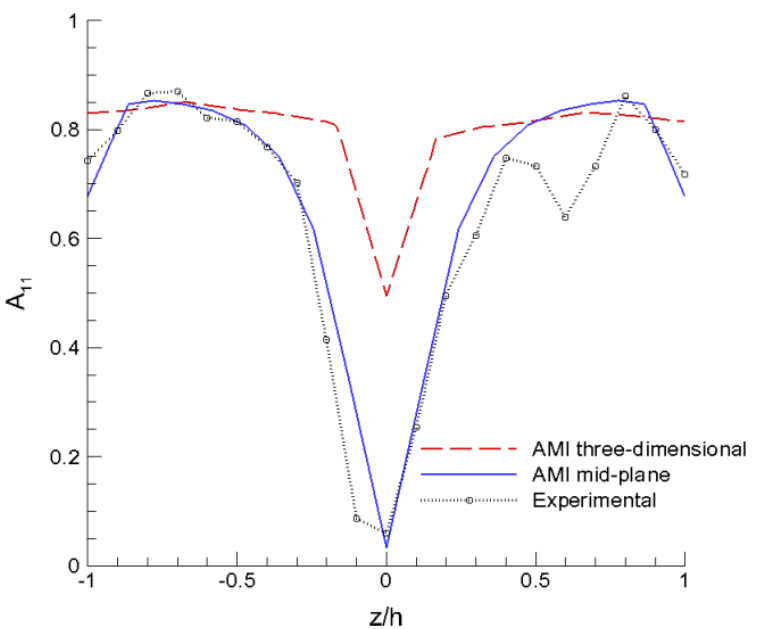

(a)

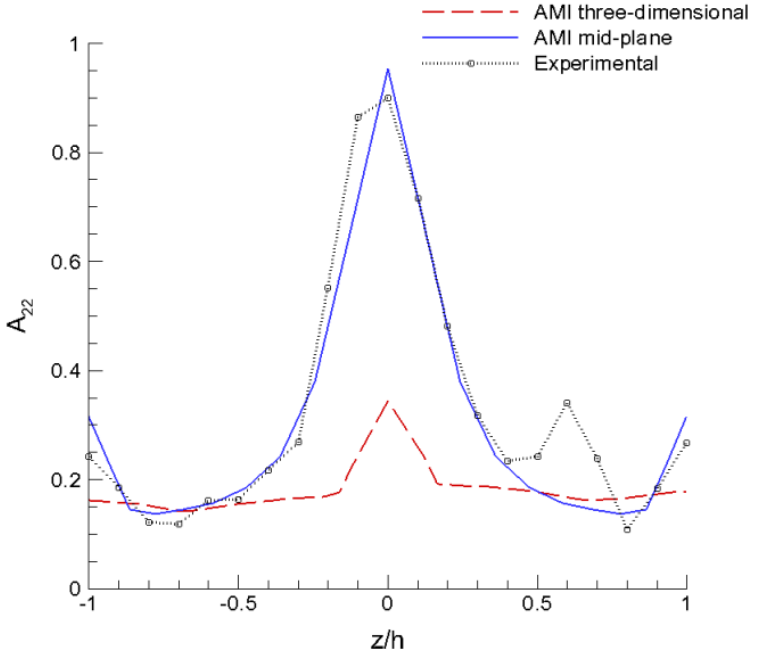

(b)

Figure 19. Predicted and measured second-order orientation tensor components (a) $A_{11}$ and (b) $A_{22}$ for Region C of the slow-fill center-gated glass/PP plaque 


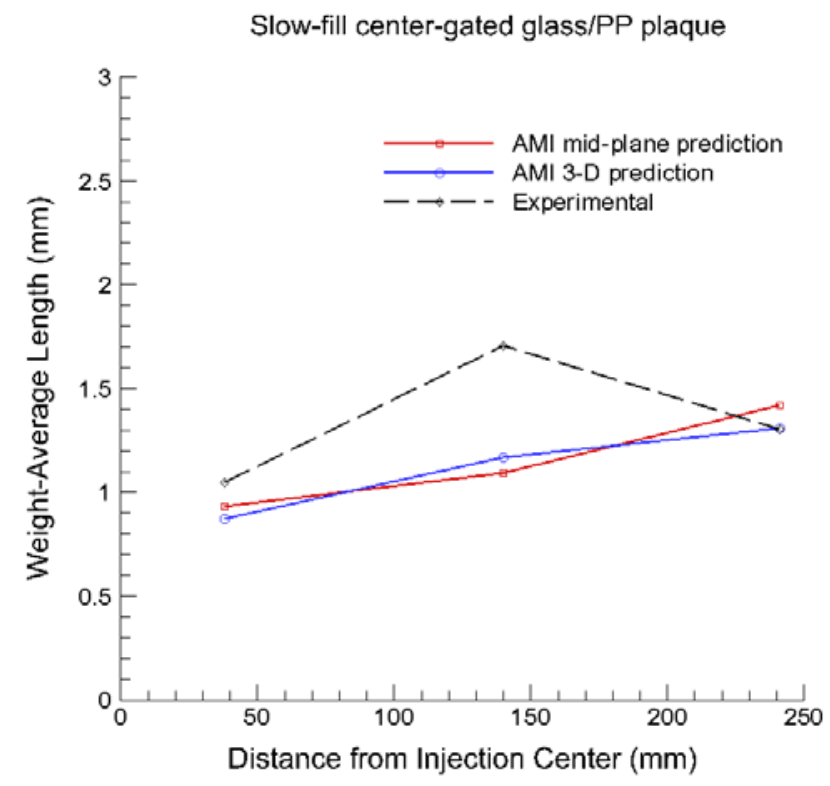

Figure 20. Predicted and experimental weight-average lengths for the slow-fill center-gated glass/PP plaque

\begin{tabular}{|c|c|c|c|}
\hline \multicolumn{5}{|c|}{ Region A } \\
\hline \multirow{2}{*}{ Average value } & Experimental & AMI mid-plane & AMI 3-D \\
\hline$A_{11}$ & 0.5605 & $0.6273(11.9 \%)$ & $0.6710(19.7 \%)$ \\
\hline \multicolumn{3}{|c|}{ Region B } \\
\hline Average value & Experimental & AMI mid-plane & AMI 3-D \\
\hline$A_{11}$ & 0.6624 & $0.6913(4.4 \%)$ & $0.7796(17.7 \%)$ \\
\hline \multicolumn{2}{|c|}{ Region C } \\
\hline Average value & Experimental & AMI mid-plane & AMI 3-D \\
\hline$A_{11}$ & 0.6442 & $0.6991(8.5 \%)$ & $0.8061(25.1 \%)$ \\
\hline
\end{tabular}

Table 10. Average values of $A_{11}$ in Regions $A, B$ and $C$ of the slow-fill center-gated glass/PP plaque 


\begin{tabular}{|c|c|c|c|}
\hline $\begin{array}{c}\text { Weight-Average } \\
\text { Length }(\mathbf{m m})\end{array}$ & Region A & Region B & Region C \\
\hline AMI mid-plane & $0.93(11.4 \%)$ & 1.09 & $1.42(9.2 \%)$ \\
\hline AMI 3-D & $0.87(17.1 \%)$ & 1.17 & $1.31(0.8 \%)$ \\
\hline Experimental & 1.05 & 1.71 & 1.3 \\
\hline
\end{tabular}

Table 11. Weight-average lengths in Regions A, B and C of the slow-fill center-gated glass/PP plaque

The results for the fast-fill edge-gated and center-gated glass/PP plaques are presented in Figures 21 to 28 . Tables 12 to 15 provide the overall assessment of the predictions for these plaques considering the $15 \%$ accuracy criterion. The same findings and observations as for the slow-fill glass/PP plaques regarding the comparison of the predicted to experimental orientation results are suggested. Good fiber length prediction has been found in trend and numerical values for the fast-fill center-gated glass/PP plaque (Figure 28).

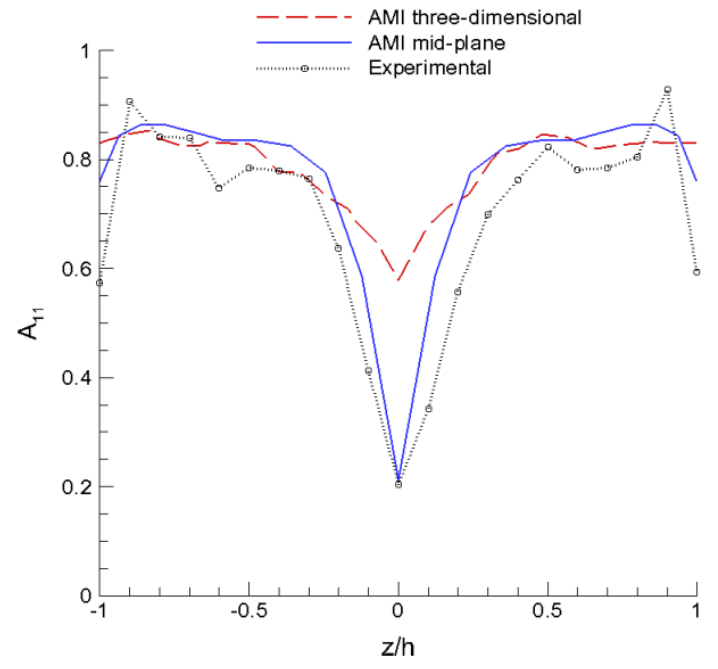

(a)

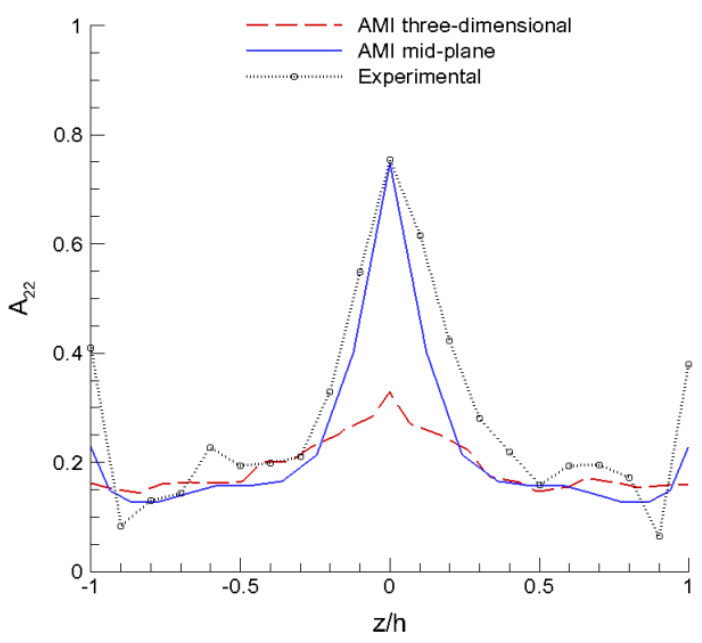

(b)

Figure 21. Predicted and measured second-order orientation tensor components (a) $A_{11}$ and (b) $A_{22}$ for Region A of the fast-fill edge-gated glass/PP plaque 


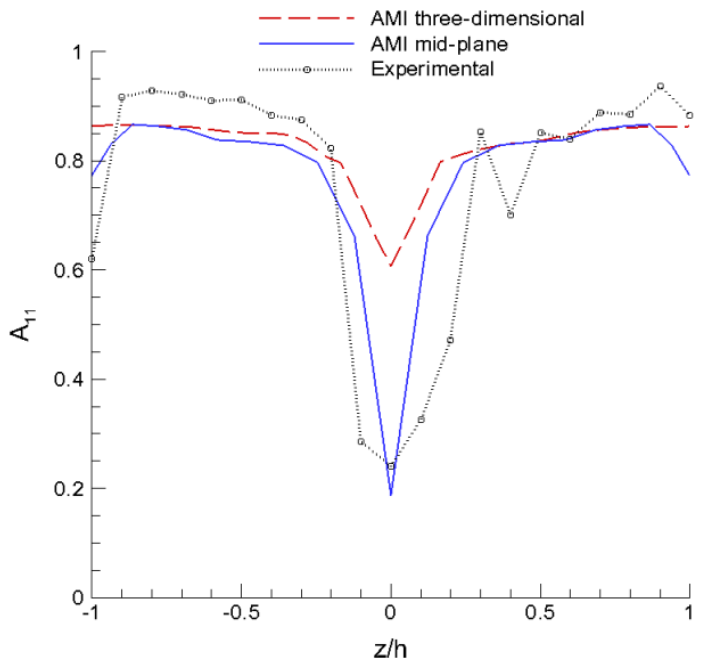

(a)

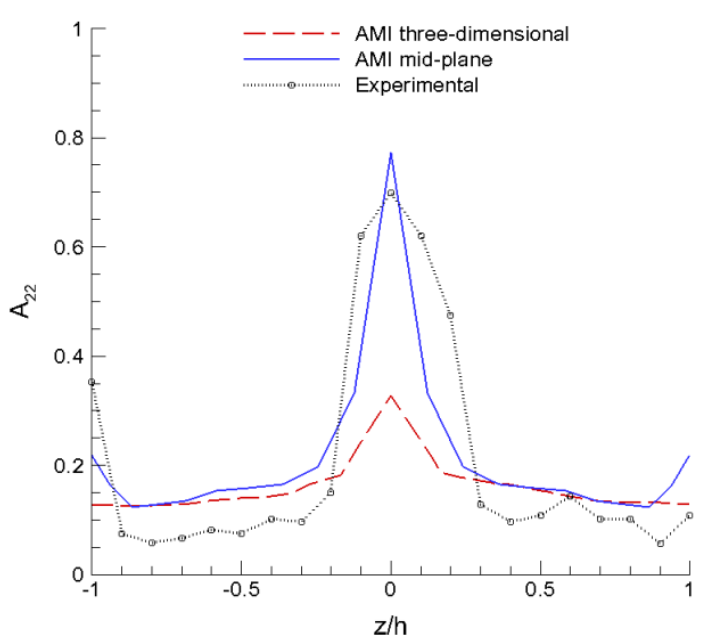

(b)

Figure 22. Predicted and measured second-order orientation tensor components (a) $A_{11}$ and (b) $A_{22}$ for Region B of the fast-fill edge-gated glass/PP plaque

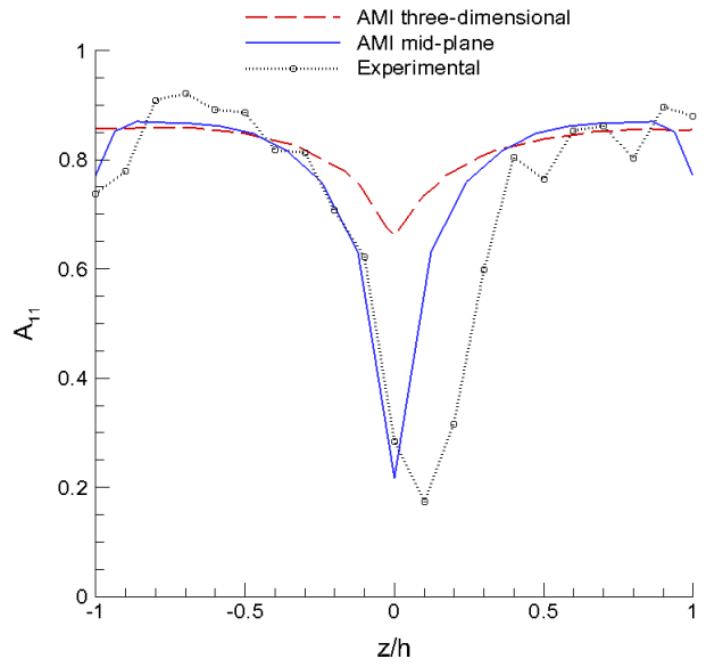

(a)

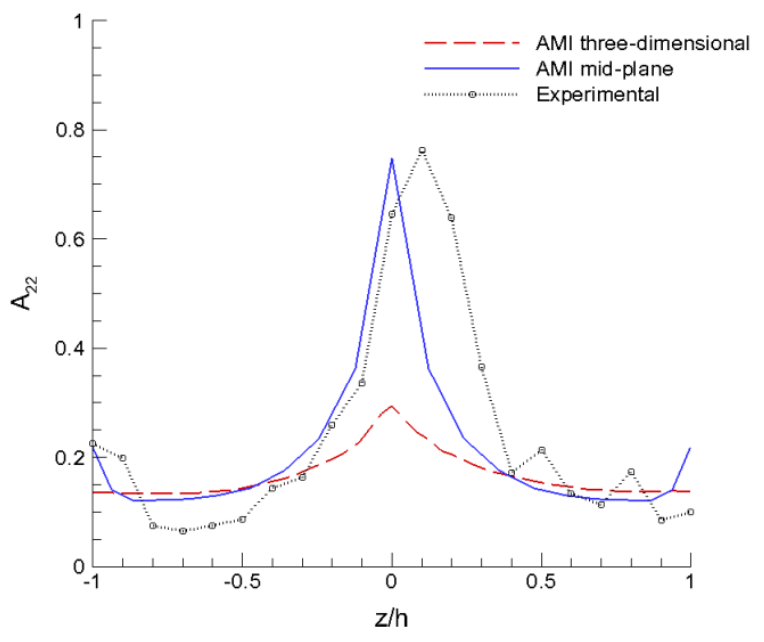

(b)

Figure 23. Predicted and measured second-order orientation tensor components (a) $A_{11}$ and (b) $A_{22}$ for Region C of the fast-fill edge-gated glass/PP plaque 


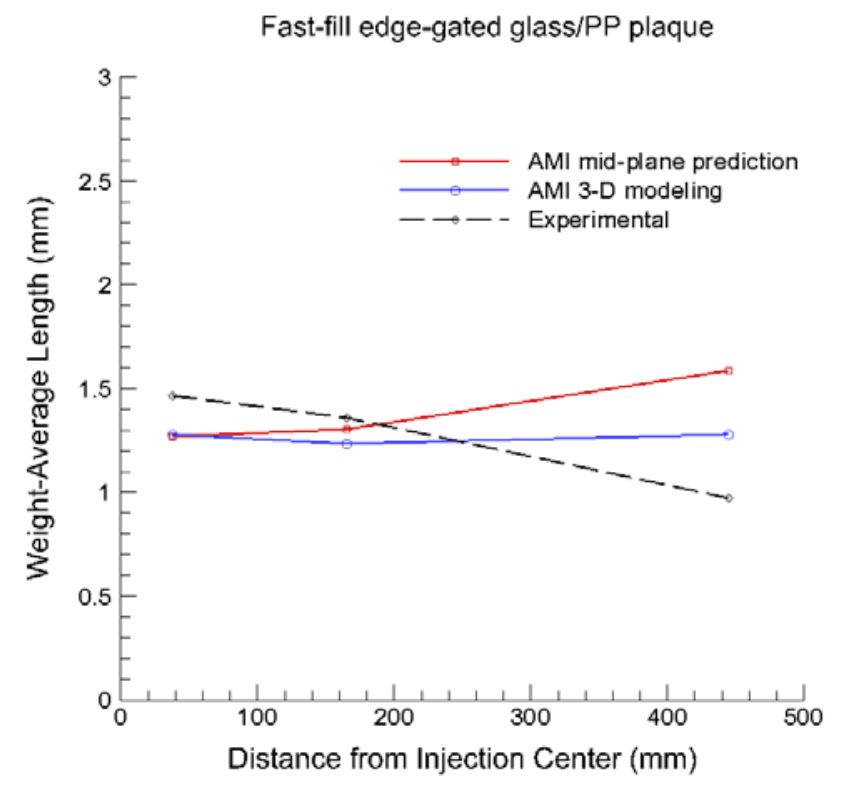

Figure 24. Predicted and experimental weight-average lengths for the fast-fill edge-gated glass/PP plaque

\begin{tabular}{|c|c|c|c|}
\hline \multicolumn{5}{|c|}{ Region A } \\
\hline \multirow{2}{*}{ Average value } & Experimental & AMI mid-plane & AMI 3-D \\
\hline$A_{11}$ & 0.6935 & $0.7754(11.8 \%)$ & $0.7876(13.6 \%)$ \\
\hline \multicolumn{5}{|c|}{ Region B } \\
\hline Average value & Experimental & AMI mid-plane & AMI 3-D \\
\hline$A_{11}$ & 0.7594 & $0.7846(3.4 \%)$ & $0.8223(8.3 \%)$ \\
\hline \multicolumn{2}{|c|}{ Region C } \\
\hline$A_{11}$ & Experimental & AMI mid-plane & AMI 3-D \\
\hline Average value & 0.7294 & $0.7856(7.8 \%)$ & $0.8195(12.4 \%)$ \\
\hline
\end{tabular}

Table 12. Average values of $A_{11}$ in Regions $A, B$ and $C$ of the fast-fill edge-gated glass/PP plaque 


\begin{tabular}{|c|c|c|c|}
\hline $\begin{array}{c}\text { Weight-Average } \\
\text { Length }(\mathbf{m m})\end{array}$ & Region A & Region B & Region C \\
\hline AMI mid-plane & $1.27(13 \%)$ & $1.3(4.4 \%)$ & 1.59 \\
\hline AMI 3-D & $1.28(12.3 \%)$ & $1.23(9.6 \%)$ & 1.28 \\
\hline Experimental & 1.46 & 1.36 & 0.97 \\
\hline
\end{tabular}

Table 13. Weight-average lengths in Regions A, B and C of the fast-fill edge-gated glass/PP plaque

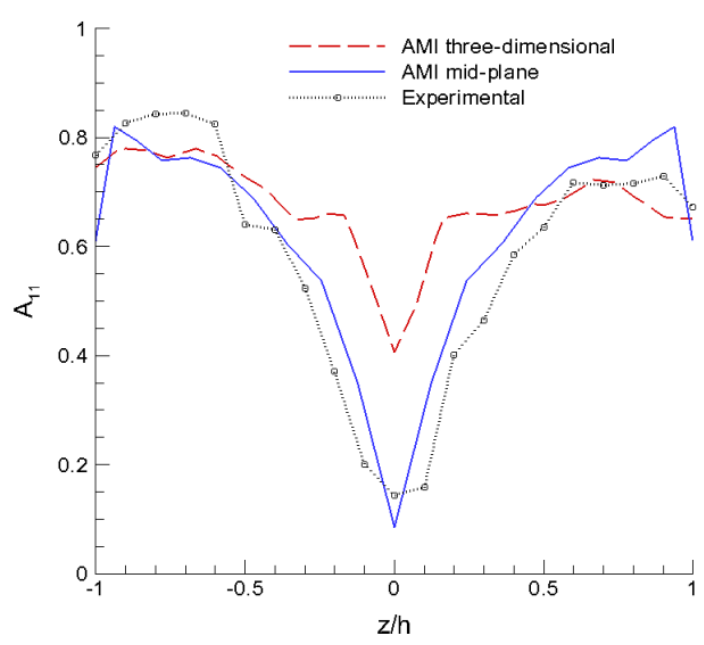

(a)

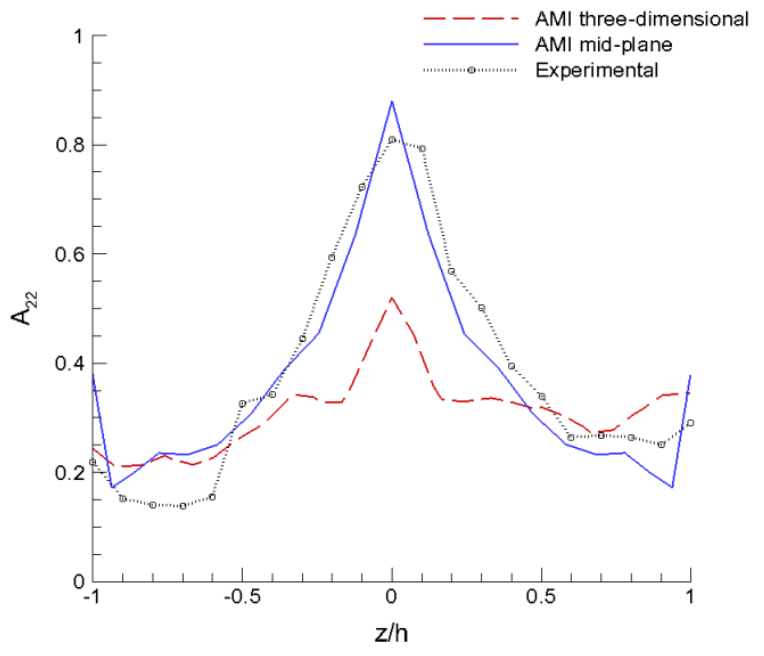

(b)

Figure 25. Predicted and measured second-order orientation tensor components (a) $A_{11}$ and (b) $A_{22}$ for Region $\mathrm{A}$ of the fast-fill center-gated glass/PP plaque 


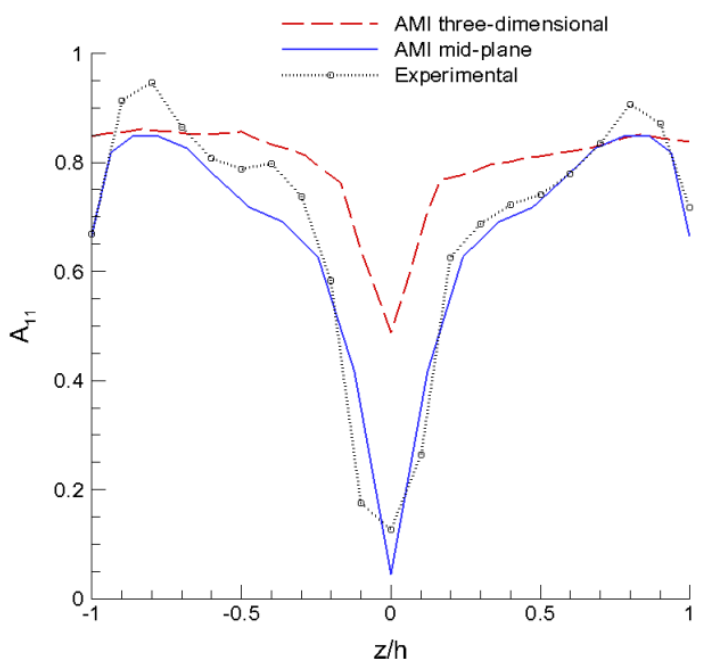

(a)

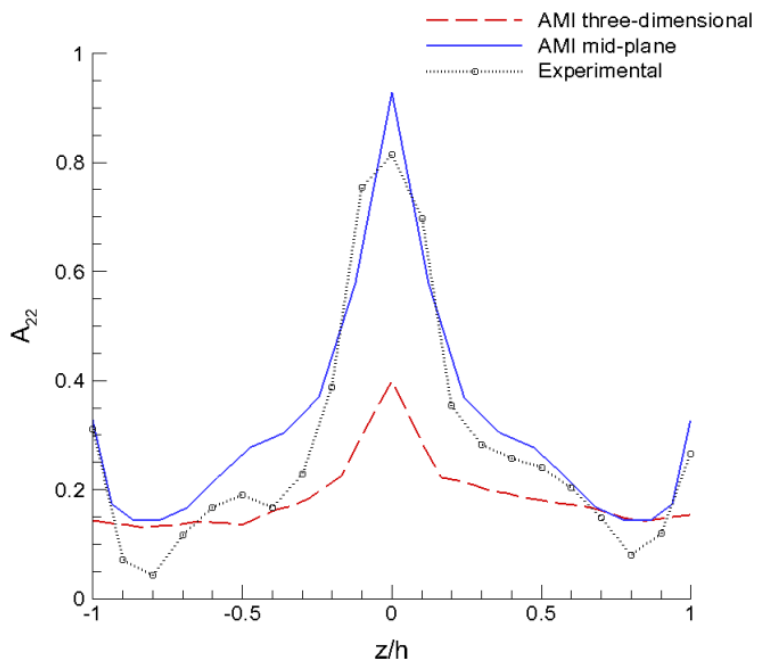

(b)

Figure 26. Predicted and measured second-order orientation tensor components (a) $A_{11}$ and (b) $A_{22}$ for Region B of the fast-fill center-gated glass/PP plaque

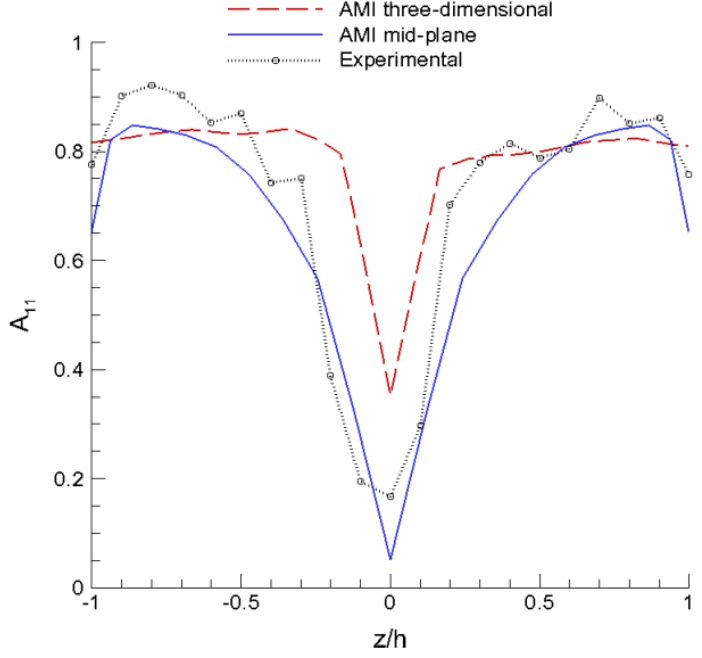

(a)

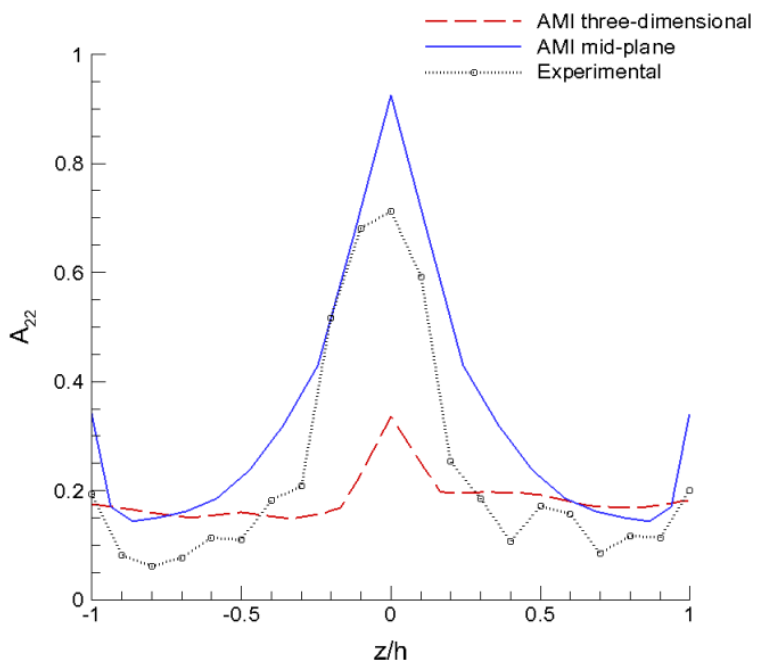

(b)

Figure 27. Predicted and measured second-order orientation tensor components (a) $A_{11}$ and (b) $A_{22}$ for Region $\mathrm{C}$ of the fast-fill center-gated glass/PP plaque 


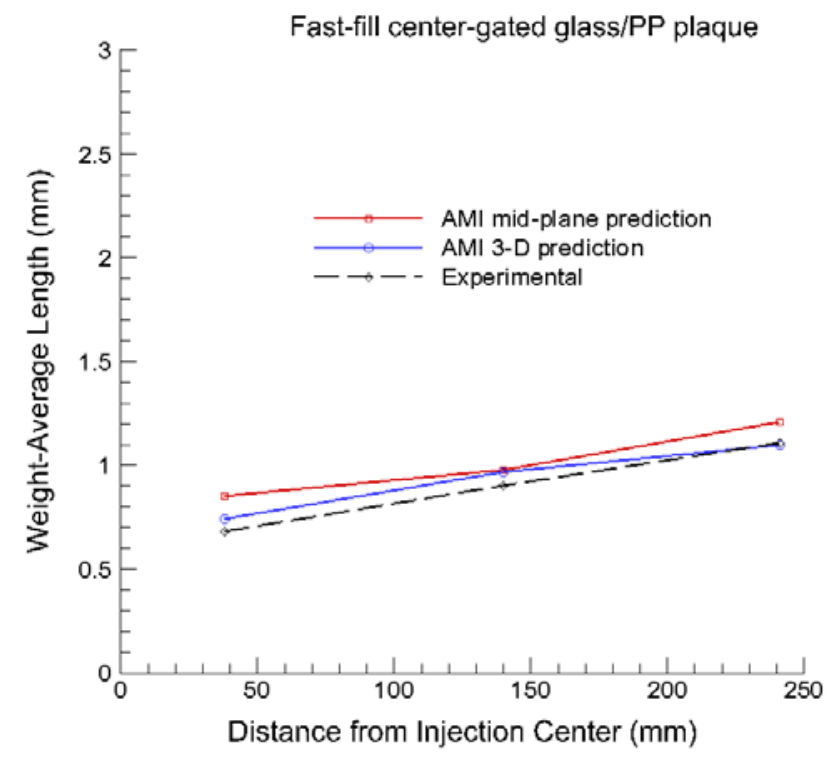

Figure 28. Predicted and experimental weight-average lengths for the fast-fill center-gated glass/PP plaque

\begin{tabular}{|c|c|c|c|}
\hline \multicolumn{5}{|c|}{ Region A } \\
\hline \multirow{2}{*}{ Average value } & Experimental & AMI mid-plane & AMI 3-D \\
\hline$A_{11}$ & 0.5906 & $0.6392(8.2 \%)$ & $0.6781(14.8 \%)$ \\
\hline \multicolumn{5}{|c|}{ Region B } \\
\hline Average value & Experimental & AMI mid-plane & AMI 3-D \\
\hline$A_{11}$ & 0.6931 & $0.6904(0.5 \%)$ & $0.7960(14.9 \%)$ \\
\hline \multicolumn{2}{|c|}{ Region C } \\
\hline$A_{11}$ & Experimental & AMI mid-plane & AMI 3-D \\
\hline Average value & 0.7154 & $0.6808(4.8 \%)$ & 0.7854 (9.8\%) \\
\hline
\end{tabular}

Table 14. Average values of $A_{11}$ in Regions $A, B$ and $C$ of the fast-fill center-gated glass/PP plaque 


\begin{tabular}{|c|c|c|c|}
\hline $\begin{array}{c}\text { Weight-Average } \\
\text { Length }(\mathbf{m m})\end{array}$ & Region A & Region B & Region C \\
\hline AMI mid-plane & $0.85(25 \%)$ & $0.98(8.9 \%)$ & $1.21(9 \%)$ \\
\hline AMI 3-D & $0.74(8.8 \%)$ & $0.97(7.8 \%)$ & $1.1(0.9 \%)$ \\
\hline Experimental & 0.68 & 0.9 & 1.11 \\
\hline
\end{tabular}

Table 15. Weight-average lengths in Regions A, B and C of the fast-fill center-gated glass/PP plaque

\subsection{Fiber Orientation and Length Results for the DuPont Glass/PA6,6 Plaques}

Fiber orientation and length results for all the glass/PA6,6 edge-gated and center-gated plaques molded under slow-fill and fast-fill conditions are given in Figures 29 to 44. Compared to the glass/PP plaques, there are similar findings and observations regarding the prediction accuracy for the glass/PA6,6 plaques. Overall, the mid-plane model accurately predicts fiber orientation for all three regions while the 3-D model can only capture the shell layers correctly. Tables 16 to 21 provide the overall assessment of the predictions for these plaques considering the $15 \%$ accuracy criterion.

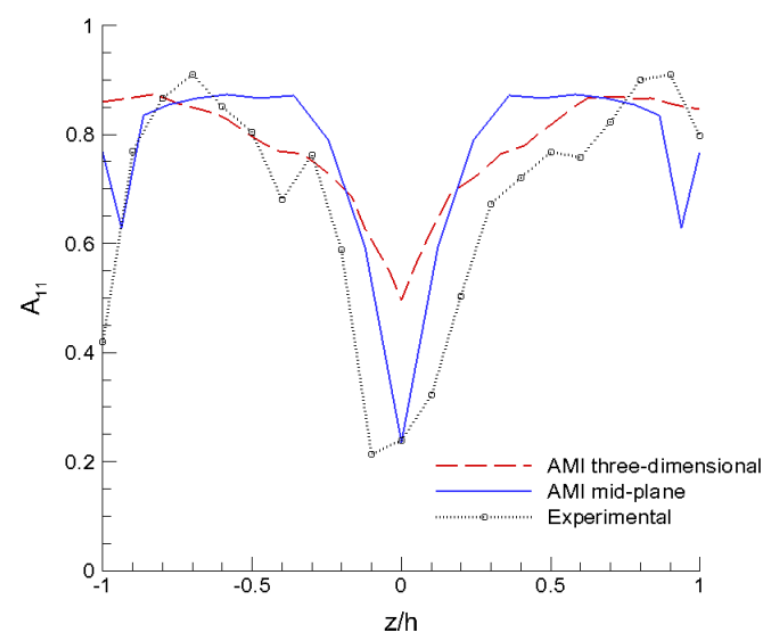

(a)

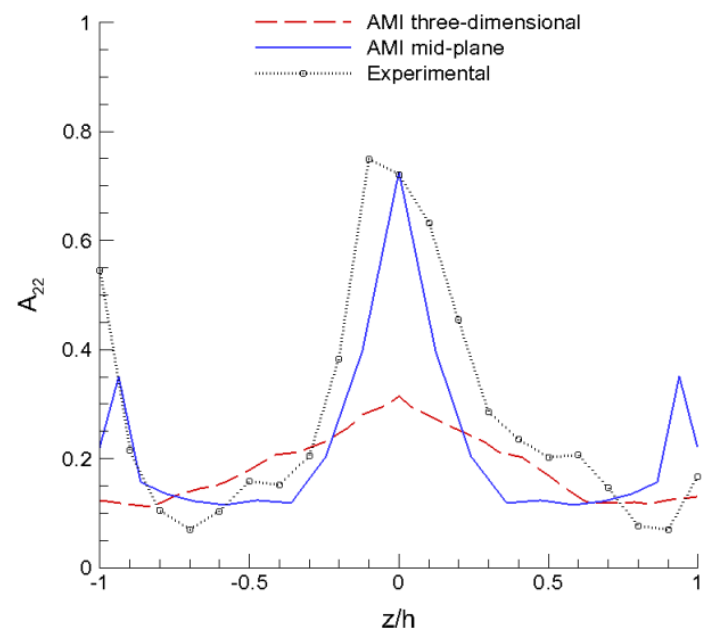

(b)

Figure 29. Predicted and measured second-order orientation tensor components (a) $A_{11}$ and (b) $A_{22}$ for Region A of the slow-fill edge-gated glass/PA6,6 plaque 


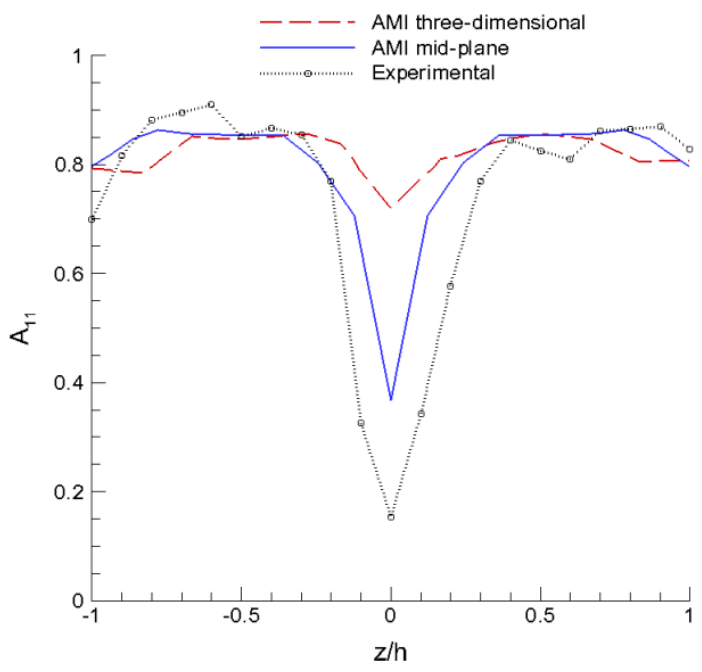

(a)

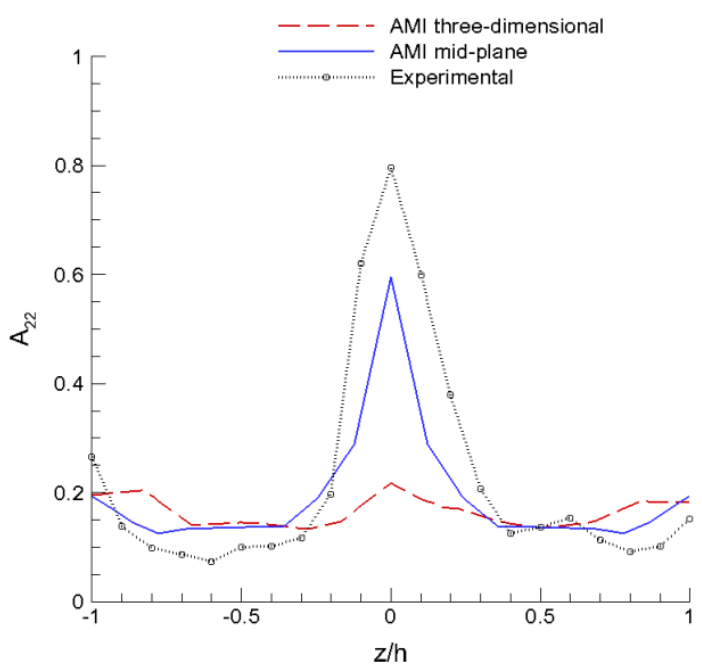

(b)

Figure 30. Predicted and measured second-order orientation tensor components (a) $A_{11}$ and (b) $A_{22}$ for Region B of the slow-fill edge-gated glass/PA6,6 plaque

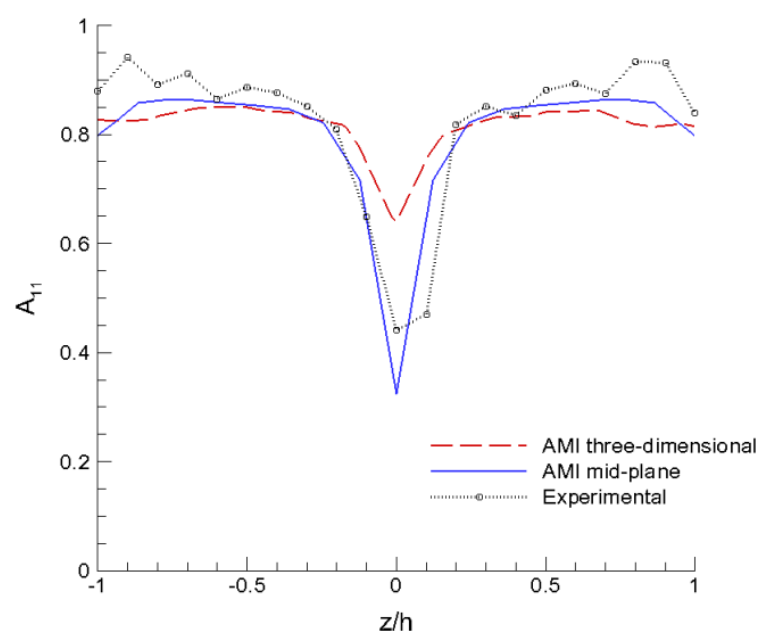

(a)

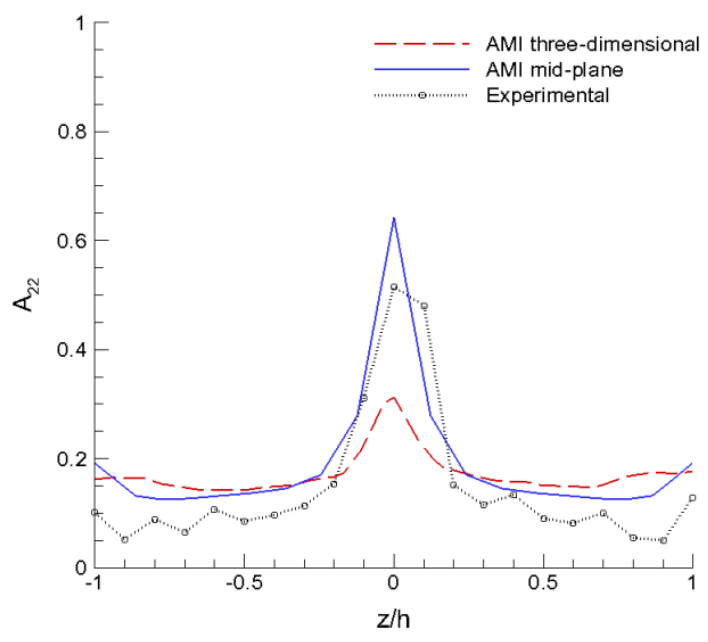

(b)

Figure 31. Predicted and measured second-order orientation tensor components (a) $A_{11}$ and (b) $A_{22}$ for Region $\mathrm{C}$ of the slow-fill edge-gated glass/PA6,6 plaque 


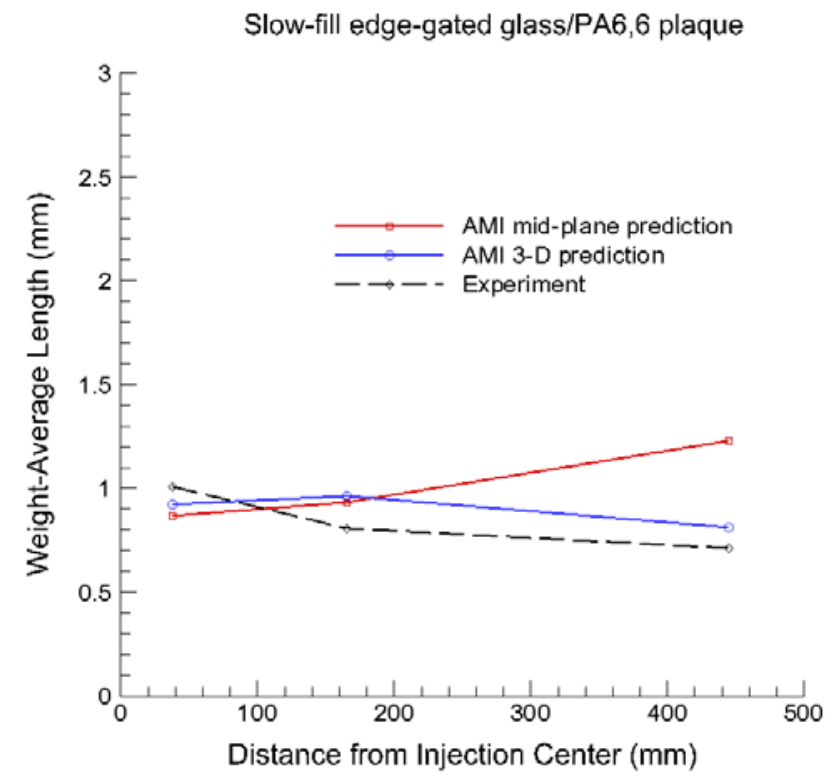

Figure 32. Predicted and experimental weight-average lengths for the slow-fill edge-gated glass/PA6,6 plaque

\begin{tabular}{|c|c|c|c|}
\hline \multicolumn{5}{|c|}{ Region A } \\
\hline \multirow{2}{*}{ Average value } & Experimental & AMI mid-plane & AMI 3-D \\
\hline$A_{11}$ & 0.6797 & $0.7311(7.6 \%)$ & $0.7798(14.7 \%)$ \\
\hline \multicolumn{5}{|c|}{ Region B } \\
\hline Average value & Experimental & AMI mid-plane & AMI 3-D \\
\hline$A_{11}$ & 0.7435 & $0.8032(8 \%)$ & $0.8220(10.6 \%)$ \\
\hline \multicolumn{1}{|c|}{ Region C } \\
\hline Average value & Experimental & AMI mid-plane & AMI 3-D \\
\hline$A_{11}$ & 0.8252 & $0.806(2.3 \%)$ & 0.8164 (1.1\%) \\
\hline
\end{tabular}

Table 16. Average values of $A_{11}$ in Regions A, B and C of the slow-fill edge-gated glass/PA6,6 plaque 


\begin{tabular}{|c|c|c|c|}
\hline $\begin{array}{c}\text { Weight-Average } \\
\text { Length }(\mathbf{m m})\end{array}$ & Region A & Region B & Region C \\
\hline AMI mid-plane & $0.87(13 \%)$ & $0.93(15 \%)$ & 1.23 \\
\hline AMI 3-D & $0.92(8 \%)$ & $0.96(18.5 \%)$ & $0.81(14.1 \%)$ \\
\hline Experimental & 1.0 & 0.81 & 0.71 \\
\hline
\end{tabular}

Table 17. Weight-average lengths in Regions A, B and C of the slow-fill edge-gated glass/PA6,6 plaque

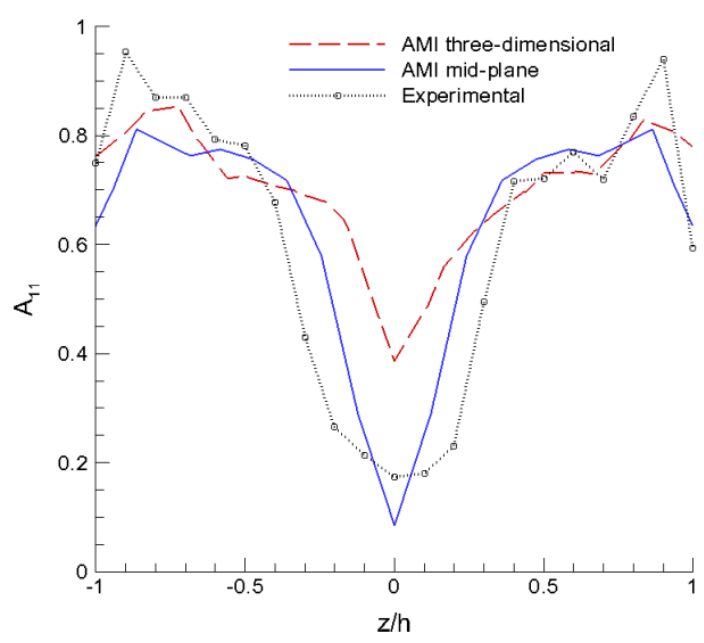

(a)

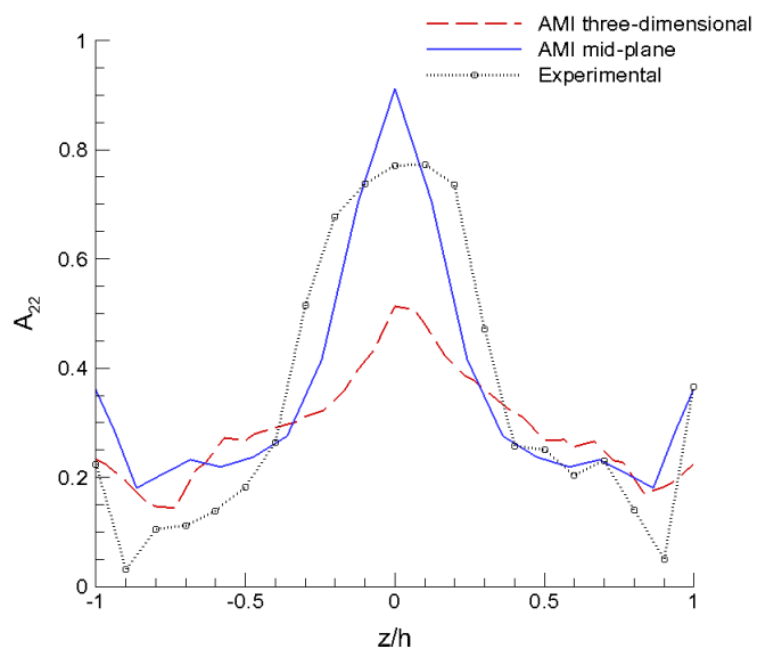

(b)

Figure 33. Predicted and measured second-order orientation tensor components (a) $A_{11}$ and (b) $A_{22}$ for Region A of the slow-fill center-gated glass/PA6,6 plaque 


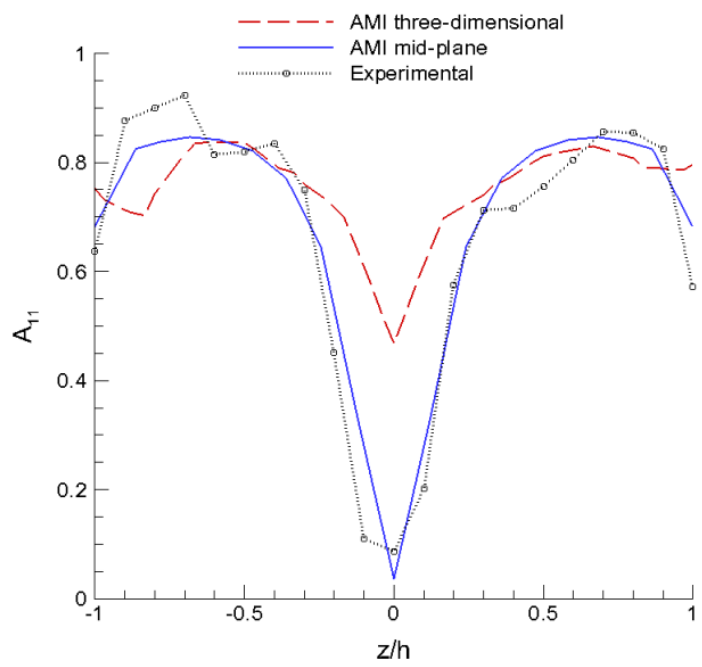

(a)

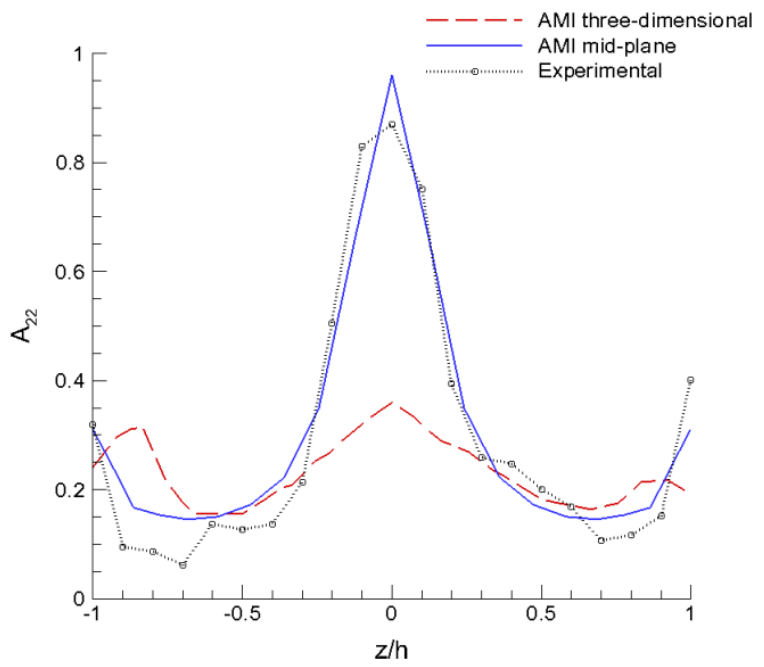

(b)

Figure 34. Predicted and measured second-order orientation tensor components (a) $A_{11}$ and (b) $A_{22}$ for Region $B$ of the slow-fill center-gated glass/PA6,6 plaque

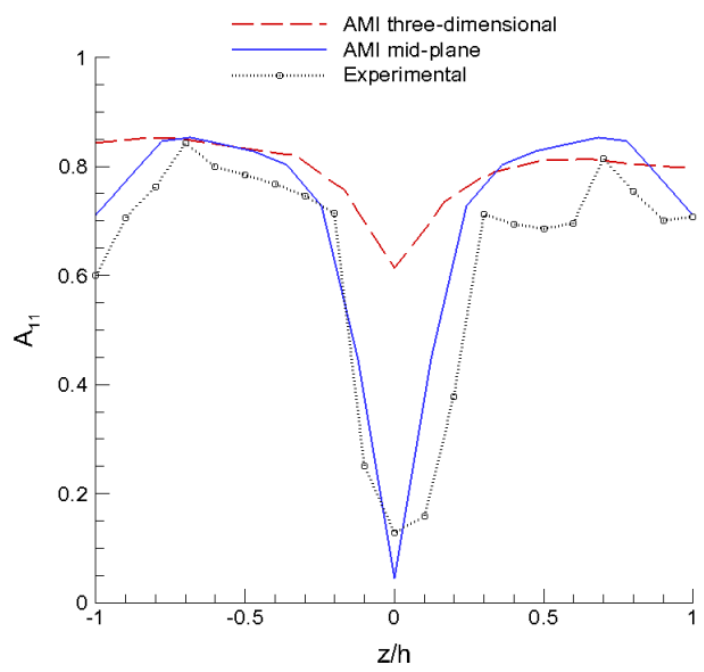

(a)

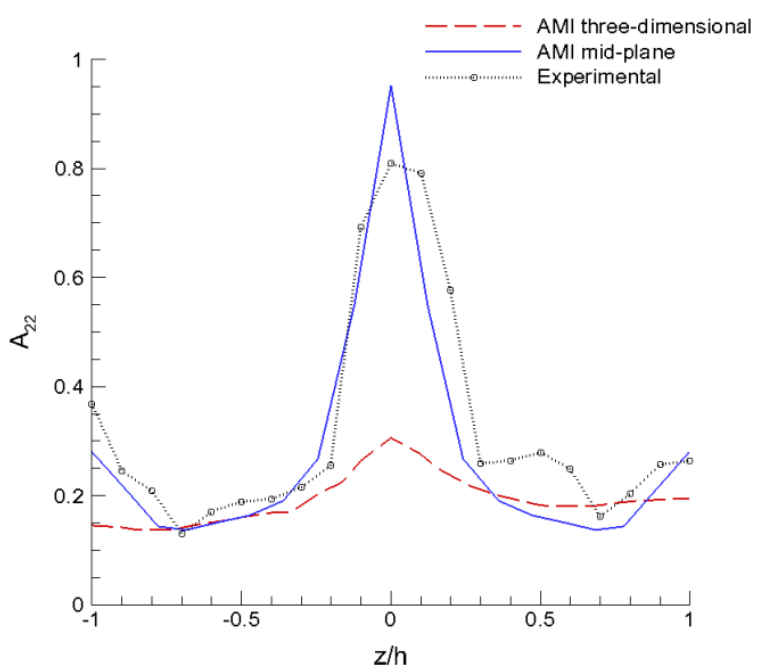

(b)

Figure 35. Predicted and measured second-order orientation tensor components (a) $A_{11}$ and (b) $A_{22}$ for Region $\mathrm{C}$ of the slow-fill center-gated glass/PA6,6 plaque 


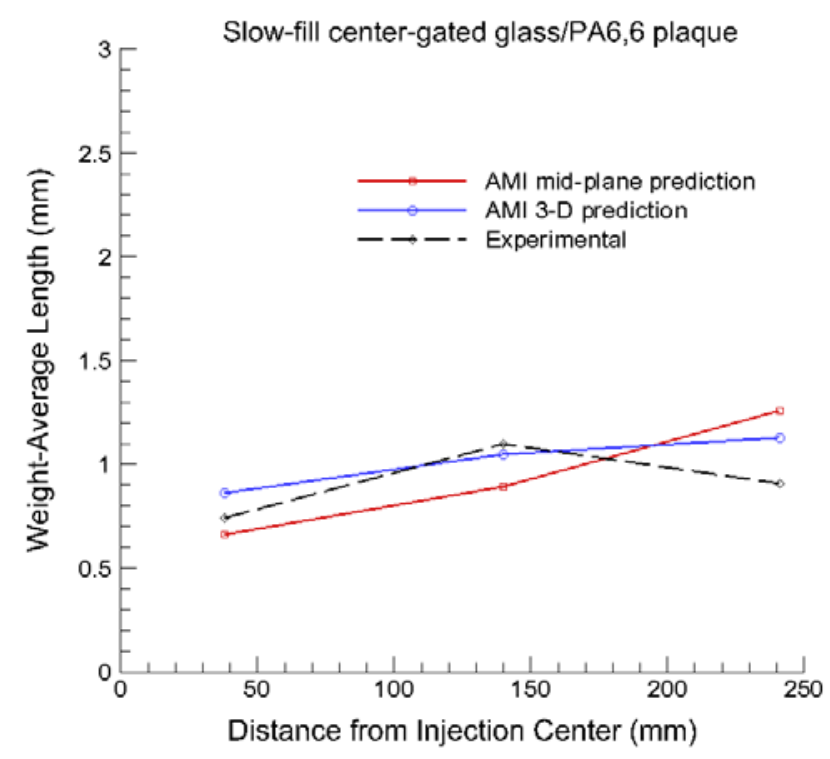

Figure 36. Predicted and experimental weight-average lengths for the slow-fill center-gated glass/PA6,6 plaque

\begin{tabular}{|c|c|c|c|}
\hline \multicolumn{5}{|c|}{ Region A } \\
\hline \multirow{2}{*}{ Average value } & Experimental & AMI mid-plane & AMI 3-D \\
\hline$A_{11}$ & 0.6178 & $0.6533(5.7 \%)$ & $0.7045(14 \%)$ \\
\hline \multicolumn{5}{|c|}{ Region B } \\
\hline Average value & Experimental & AMI mid-plane & AMI 3-D \\
\hline$A_{11}$ & 0.6702 & $0.7015(4.7 \%)$ & $0.7458(11.3 \%)$ \\
\hline \multicolumn{1}{|c|}{ Region C } \\
\hline Average value & Experimental & AMI mid-plane & AMI 3-D \\
\hline$A_{11}$ & 0.6382 & $0.7258(13.7 \%)$ & $0.7956(25 \%)$ \\
\hline
\end{tabular}

Table 18. Average values of $A_{11}$ in Regions $A, B$ and $C$ of the slow-fill center-gated glass/PA6,6 plaque 


\begin{tabular}{|c|c|c|c|}
\hline $\begin{array}{c}\text { Weight-Average } \\
\text { Length }(\mathbf{m m})\end{array}$ & Region A & Region B & Region C \\
\hline AMI mid-plane & $0.66(10.8 \%)$ & $0.89(19.1 \%)$ & 1.26 \\
\hline AMI 3-D & $0.86(16.2 \%)$ & $1.05(5 \%)$ & 1.13 \\
\hline Experimental & 0.74 & 1.1 & 0.91 \\
\hline
\end{tabular}

Table 19. Weight-average lengths in Regions A, B and C of the slow-fill center-gated glass/PA6,6 plaque

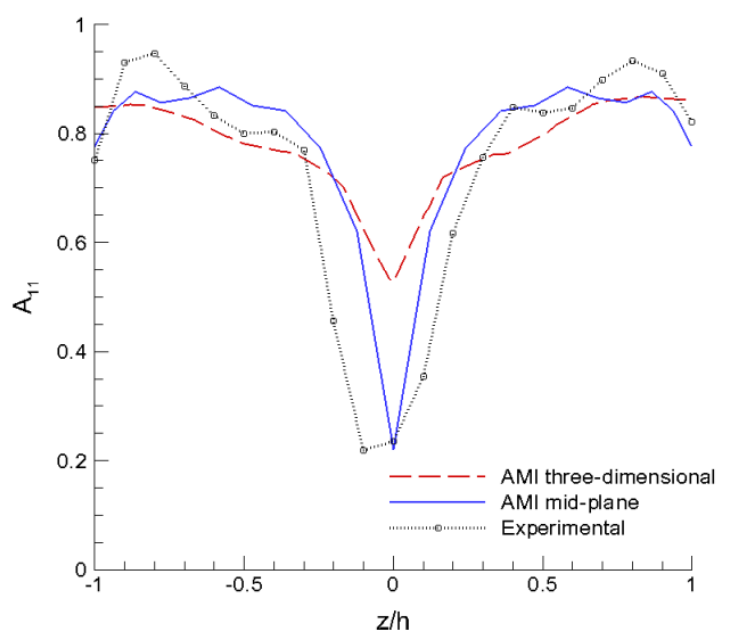

(a)

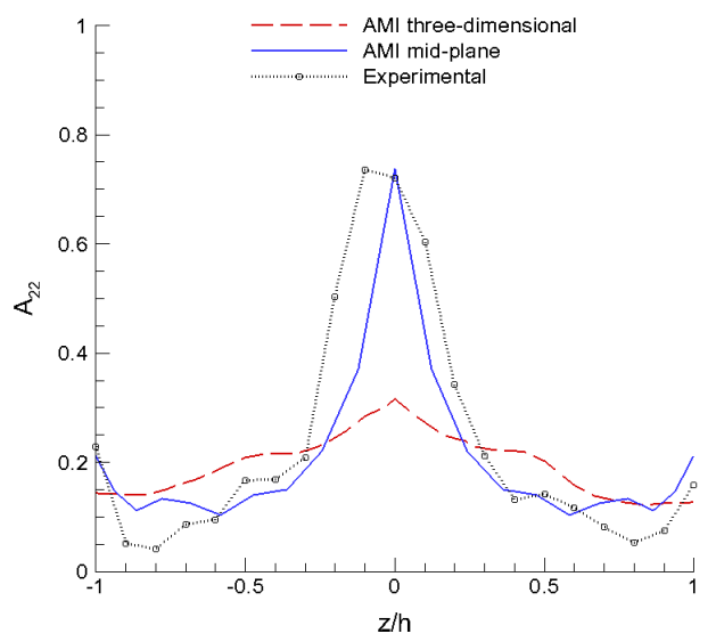

(b)

Figure 37. Predicted and measured second-order orientation tensor components (a) $A_{11}$ and (b) $A_{22}$ for Region A of the fast-fill edge-gated glass/PA6,6 plaque 


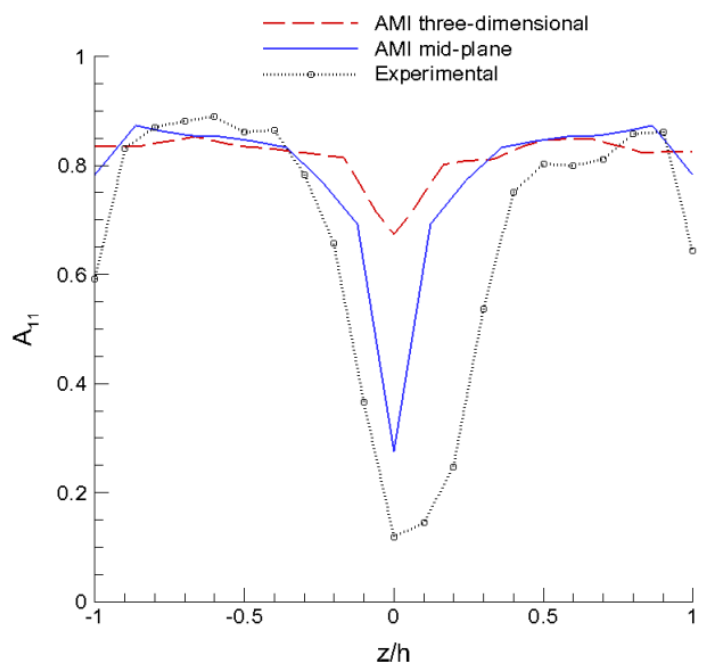

(a)

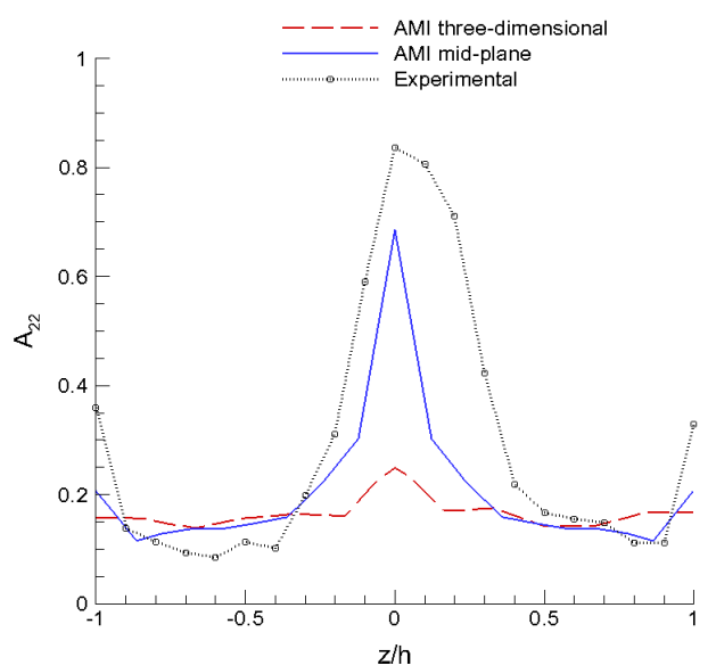

(b)

Figure 38. Predicted and measured second-order orientation tensor components (a) $A_{11}$ and (b) $A_{22}$ for Region B of the fast-fill edge-gated glass/PA6,6 plaque

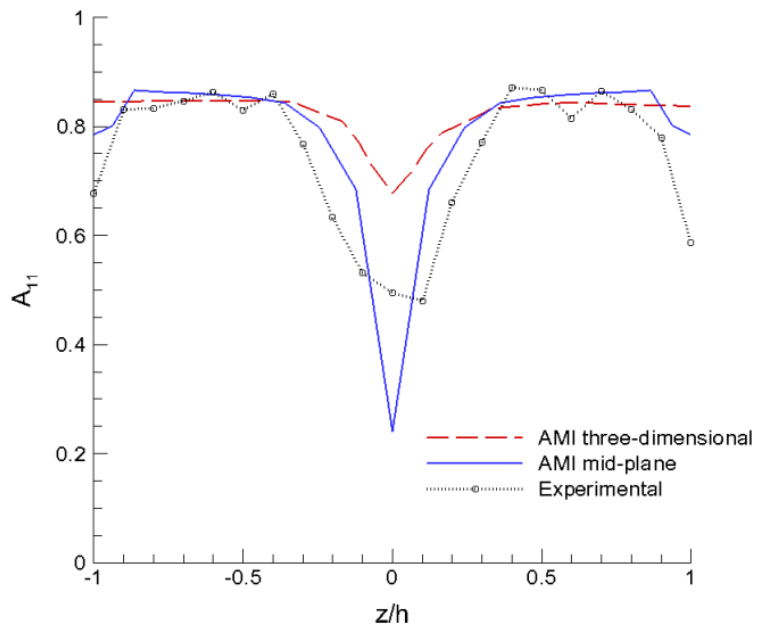

(a)

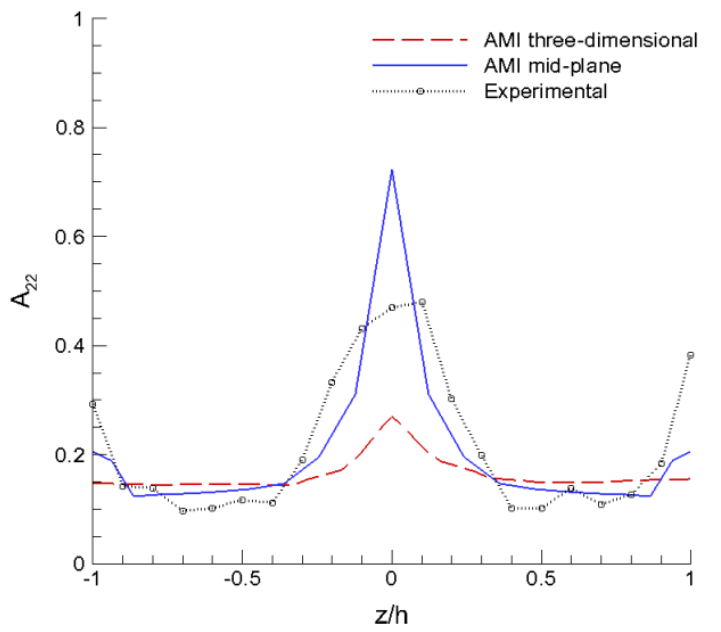

(b)

Figure 39. Predicted and measured second-order orientation tensor components (a) $A_{11}$ and (b) $A_{22}$ for Region $C$ of the fast-fill edge-gated glass/PA6,6 plaque 


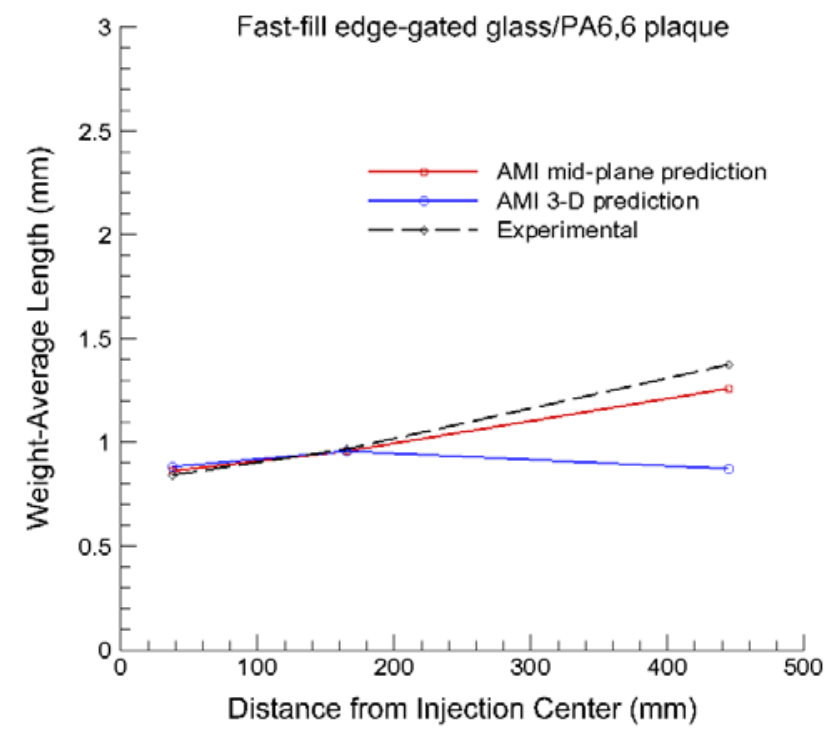

Figure 40. Predicted and experimental weight-average lengths for the fast-fill edge-gated glass/PA6,6 plaque

\begin{tabular}{|c|c|c|c|}
\hline \multicolumn{5}{|c|}{ Region A } \\
\hline \multirow{2}{*}{ Average value } & Experimental & AMI mid-plane & AMI 3-D \\
\hline$A_{11}$ & 0.7356 & $0.79(7.4 \%)$ & $0.7758(5.5 \%)$ \\
\hline \multicolumn{5}{|c|}{ Region B } \\
\hline Average value & Experimental & AMI mid-plane & AMI 3-D \\
\hline$A_{11}$ & 0.6747 & $0.7933(17.6 \%)$ & $0.8169(21.1 \%)$ \\
\hline \multicolumn{1}{|c|}{ Region C } \\
\hline$A_{11}$ & Experimental & AMI mid-plane & AMI 3-D \\
\hline
\end{tabular}

Table 20. Average values of $A_{11}$ in Regions $A, B$ and $C$ of the fast-fill edge-gated glass/PA6,6 plaque 


\begin{tabular}{|c|c|c|c|}
\hline $\begin{array}{c}\text { Weight-Average } \\
\text { Length }(\mathbf{m m})\end{array}$ & Region A & Region B & Region C \\
\hline AMI mid-plane & $0.863(2.3 \%)$ & $0.957(0.8 \%)$ & $1.256(8.7 \%)$ \\
\hline AMI 3-D & $0.881(4.4 \%)$ & $0.956(0.9 \%)$ & 0.873 \\
\hline Experimental & 0.844 & 0.965 & 1.376 \\
\hline
\end{tabular}

Table 21. Weight-average lengths in Regions $A, B$ and $C$ of the fast-fill edge-gated glass/PA6,6 plaque

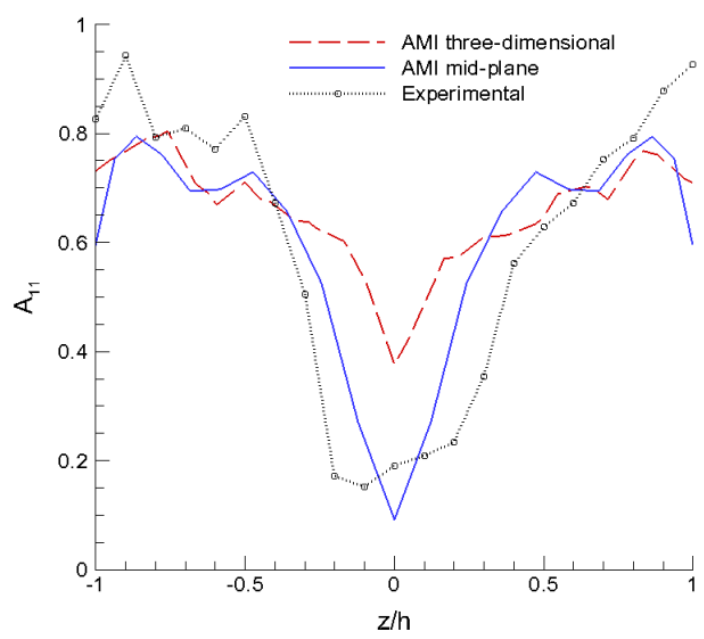

(a)

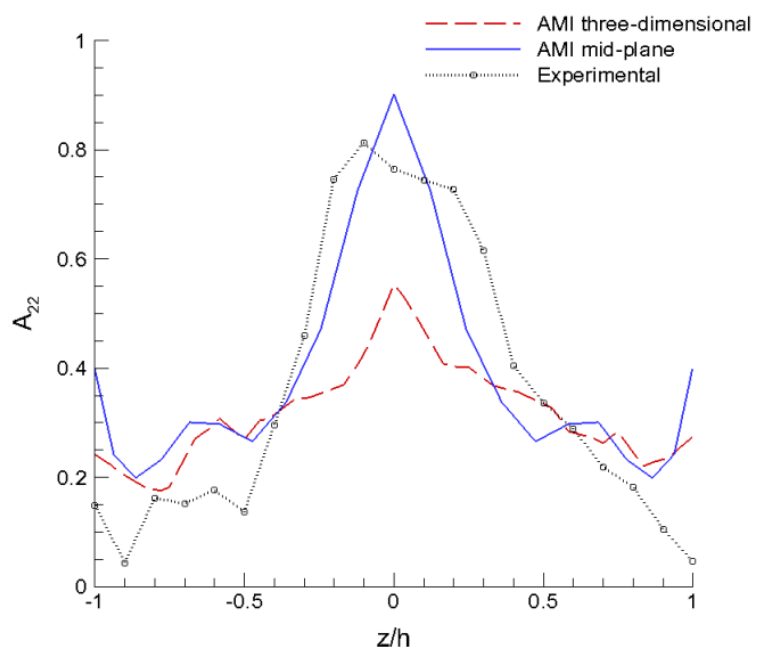

(b)

Figure 41. Predicted and measured second-order orientation tensor components (a) $A_{11}$ and (b) $A_{22}$ for Region A of the fast-fill center-gated glass/PA6,6 plaque 


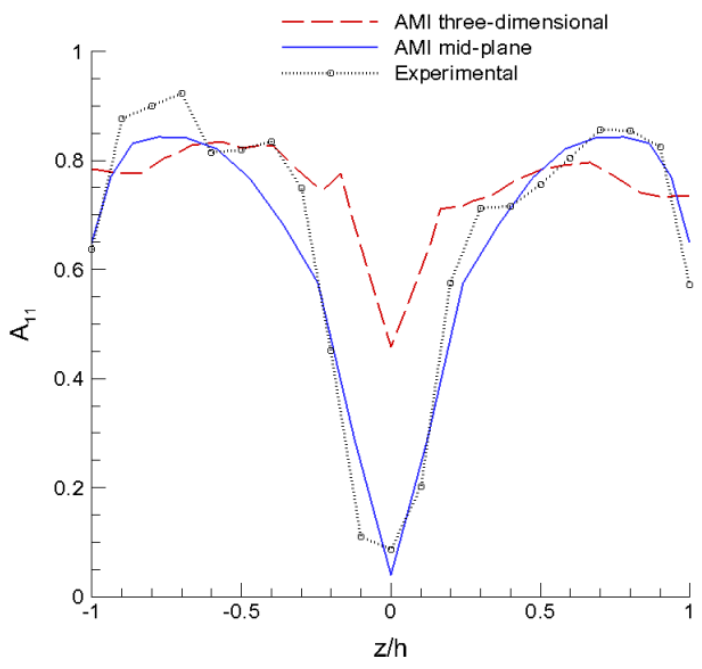

(a)

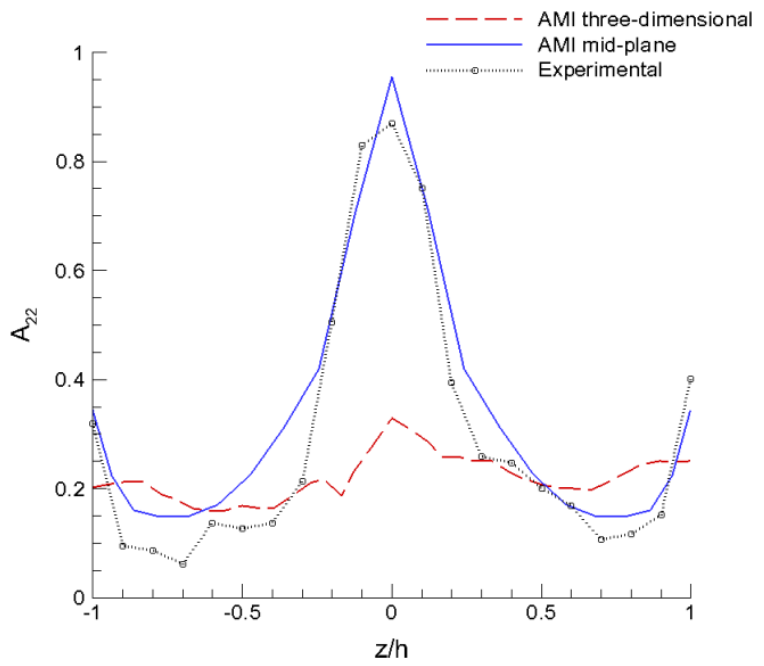

(b)

Figure 42. Predicted and measured second-order orientation tensor components (a) $A_{11}$ and (b) $A_{22}$ for Region B of the fast-fill center-gated glass/PA6,6 plaque

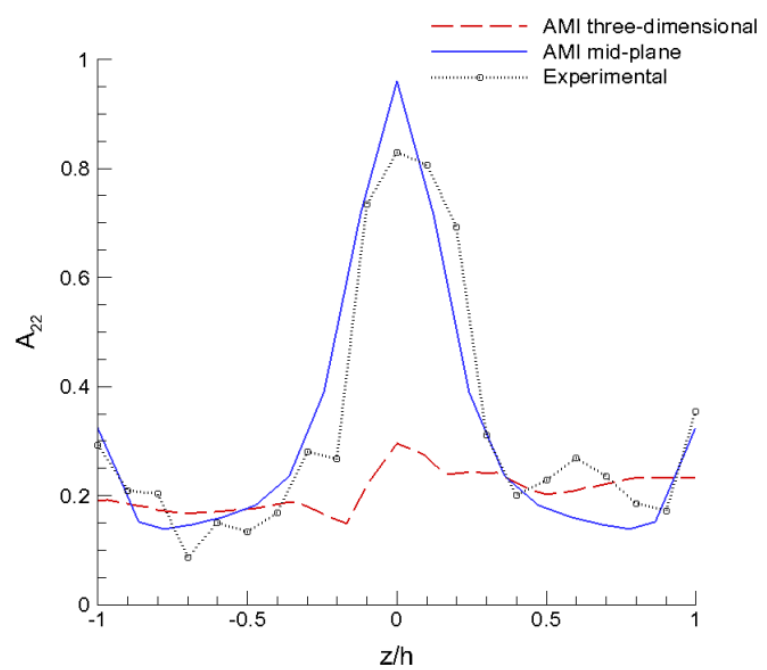

(a)

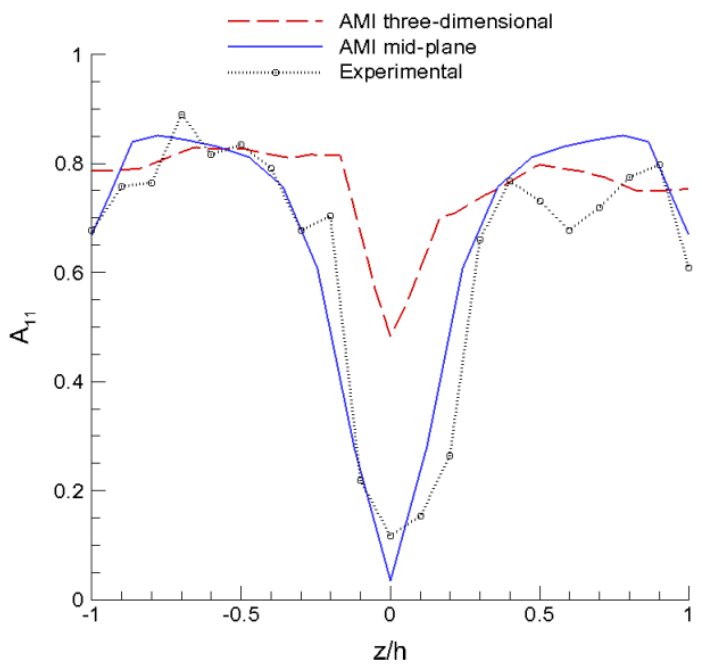

(b)

Figure 43. Predicted and measured second-order orientation tensor components (a) $A_{11}$ and (b) $A_{22}$ for Region $C$ of the fast-fill center-gated glass/PA6,6 plaque 


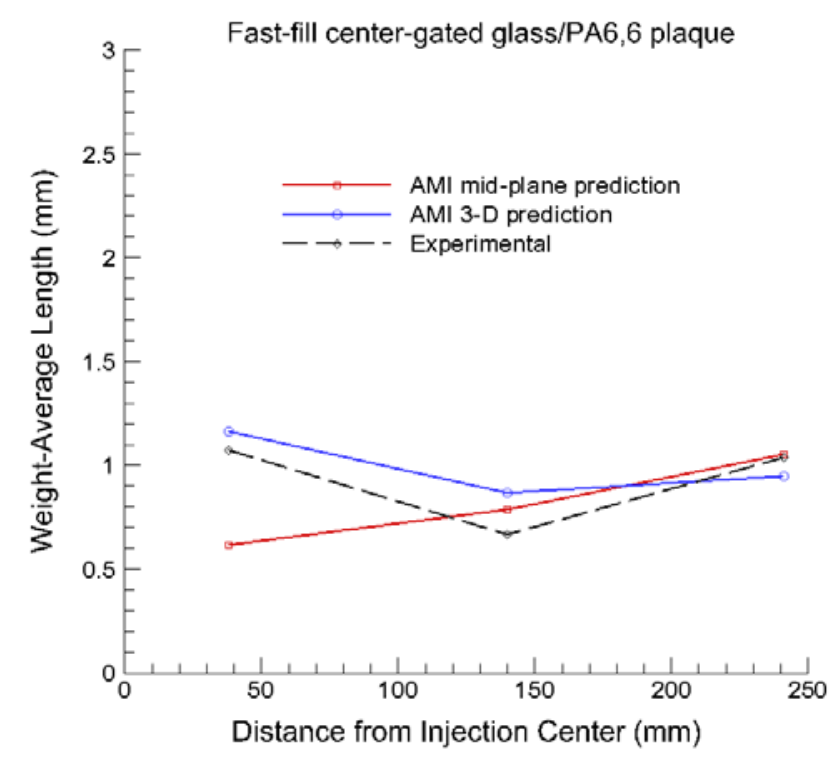

Figure 44. Predicted and experimental weight-average lengths for the fast-fill center-gated glass/PA6,6 plaque

\begin{tabular}{|c|c|c|c|}
\hline \multicolumn{5}{|c|}{ Region A } \\
\hline \multirow{2}{*}{ Average value } & Experimental & AMI mid-plane & AMI 3-D \\
\hline$A_{11}$ & 0.6034 & $0.6210(3 \%)$ & $0.6605(9.5 \%)$ \\
\hline \multicolumn{4}{|c|}{ Region B } \\
\hline Average value & Experimental & AMI mid-plane & AMI 3-D \\
\hline$A_{11}$ & 0.6702 & $0.6751(0.8 \%)$ & $0.7498(11.9 \%)$ \\
\hline \multicolumn{1}{|c|}{ Region C } \\
\hline$A_{11}$ & Experimental & AMI mid-plane & AMI 3-D \\
\hline
\end{tabular}

Table 22. Average values of $A_{11}$ in Regions $A, B$ and $C$ of the fast-fill center-gated glass/PA6,6 plaque 


\begin{tabular}{|c|c|c|c|}
\hline $\begin{array}{c}\text { Weight-Average } \\
\text { Length }(\mathbf{m m})\end{array}$ & Region A & Region B & Region C \\
\hline AMI mid-plane & 0.615 & $0.785(17.9 \%)$ & $1.05(1 \%)$ \\
\hline AMI 3-D & $1.16(8.4 \%)$ & 0.866 & $0.948(8.8 \%)$ \\
\hline Experimental & 1.07 & 0.667 & 1.04 \\
\hline
\end{tabular}

Table 23. Weight-average lengths in Regions $A, B$ and $C$ of the fast-fill center-gated glass/PA6,6 plaque

\subsection{Conclusions}

Mid-plane and 3-D models based on the 2013 research version of Moldflow were built for the injection molding simulations of $600 \mathrm{~mm}$ x $600 \mathrm{~mm}$ × $3 \mathrm{~mm}$ ACC plaques from 40\%/w glass/polypropylene (Dow Chemical DLGF9411.00) and 40\%/w glass/polyamide 6,6 (DuPont Zytel 75LG40HSL BK031) materials. The models capture two experimental fill speeds and gating conditions to achieve flows in edge-gated and center-gated plaques under slow-fill and fast-fill conditions. The ARD-RSC fiber orientation model and fiber length attrition model in the mold were used to predict fiber orientation and length distributions in the studied plaques. We draw the following conclusions from the analyses:

- The Moldflow mid-plane models provide accurate fiber orientation predictions for all the studied cases.

- Currently, the Moldflow 3-D models do not provide as accurate results as the mid plane models but can fairly capture the slight asymmetry in orientation with respect to the plaque mid plane observed in experiments.

- At the time of this report, the Moldflow mid-plane and 3-D models qualitatively predict weight-average lengths in the studied plaques. More data are needed for model validation and for the understanding of the opposed trends of length variations from the gate to the plaque end in many cases.

\subsection{Acknowledgements}

The authors would like to thank the support of the US Department of Energy's Office of Vehicle Technologies - EERE, in particular, Dr. Carol Schutte. 


\subsection{References}

[1] Phelps JH and Tucker III CL (2009). “An Anisotropic Rotary Diffusion Model for Fiber Orientation in Short- and Long-Fiber Thermoplastics," Journal of the Non-Newtonian Fluid Mechanics, 156(3):165-176.

[2] Phelps JH (2009). "Processing-Microstructural Models for Short- and Long-Fiber Thermoplastic Composites,” PhD Thesis, University of Illinois at Urbana-Champaign, Urbana, IL 61801.

[3] Nguyen BN, Jin X, Wang J, Phelps JH, Tucker III CL, Kunc V, Bapanapalli SK, Smith MT (2010). "Implementation of New Process Models for Tailored Polymer Composite Structures into Processing Software Packages.” PNNL/Autodesk CRADA Nr. 260 Report, Pacific Northwest National Laboratory, PNNL-19185.

[4] Folgar F and Tucker III CL (1984). "Orientation Behavior of Fibers in Concentrated Suspensions,” Journal of Reinforced Plastic Composites, 3, 98-119.

[5] Phan-Thien N, Fan X-J, Tanner RI, and Zheng R (2002). "Folgar-Tucker Constant for a Fibre Suspension in a Newtonian Fluid,” Journal of Non-Newtonian Fluid Mechanics, 103:251260.

[6] Wang J (2007). “Improved Fiber Orientation Predictions for Injection Molded Composites,” PhD Thesis, University of Illinois at Urbana-Champaign, Urbana, IL 61801

[7] Dinh SM and Armstrong RC (1984). "A Rheological Equation of State for SemiConcentrated Fiber Suspensions,” Journal of Rheology, 28(3):207-227.

[8] Autodesk Simulation Moldflow Synergy 2013, Autodesk, Inc. 